\section{$\Delta$ rkivoc

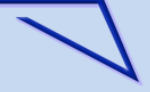

Archive for

Organic Chemistry
The Free Internet Journal

for Organic Chemistry
Review

Arkivoc 2017, part i, 41-66

\title{
Recent advances in ipso-nitration reactions
}

\author{
Khurshed Bozorov, ${ }^{\mathrm{a}, \mathrm{b}}$ Jiang-Yu Zhao, ${ }^{\mathrm{a}}$ and Haji A. Aisa*a
}

${ }^{a}$ Key Laboratory of Plant Resources and Chemistry in Arid Regions, Xinjiang Technical Institute of Physics and Chemistry, Chinese Academy of Sciences, South Beijing Road 40-1, Urumqi, Xinjiang 830011 , PR China

${ }^{b}$ Institute of the Chemistry of Plant Substances, Academy of Sciences of Uzbekistan,

Mirzo Ulugbek str. 77, Tashkent 100 170, Uzbekistan

E-mail: haji@ms.xjb.ac.cn

Received 08-23-2016

Accepted 11-08-2016

Published on line 12-26-2016

\section{Abstract}

In the present review the various types of ipso-nitration reactions, in particular those advances in ipsonitration reactions that have been reported since the beginning of this century (i.e., from 2000-2015) are discussed. The review highlights the recent developments of the ipso-nitration reactions, a variety of the differences between traditional and modern methods for performing ipso-nitration reactions, as well as the most novel approaches to performing these reactions. In addition, the proposed mechanisms of ipso-nitration reactions are discussed.

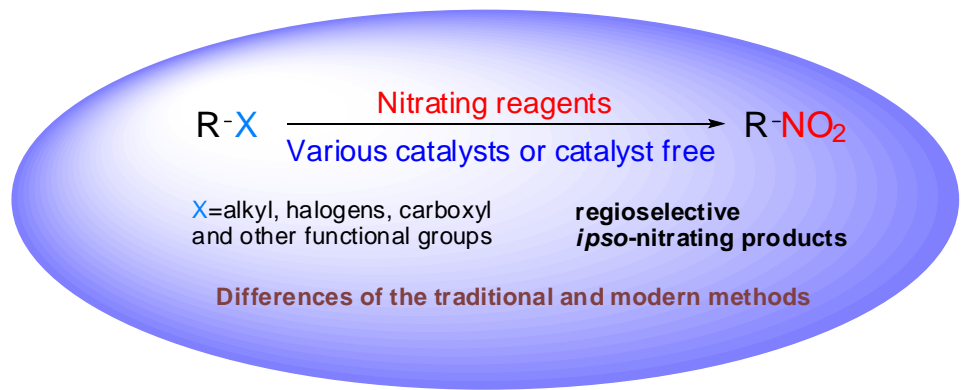

Keywords: ipso-Nitration, calixarenes, arylboronic acids 


\section{Table of Contents}

1. Introduction

2. Developments in Traditional ipso-Nitration

2.1 ipso-Nitration of macromolecules (calixarenes)

2.2 ipso-Nitration of heterocycles

2.3.Cerium (IV) ammonium nitrate (CAN) as nitrating agent

3. Modern Approaches to ipso-Nitration

3.1 ipso-Nitration of carboxylic groups

3.2 ipso-Nitration of halogens

3.3 ipso-Nitration of arylboronic acids

\section{Introduction}

The nitration ${ }^{1,2}$ of organic compounds (aliphatic, aromatic, heterocyclic, and others) is one of the key reactions of both organic synthesis and organic chemistry in general. ${ }^{3,4}$ Moreover, nitro compounds are actually used by pharmacists and medicinal chemists in their investigations, most commonly as building blocks, lead compounds, and intermediates for drug discovery efforts. ${ }^{5-7}$ The functional groups (methyl, ethyl, propyl, butyl, halogens, hydroxyl, carbonyl, carboxyl, and others) that are attached to aliphatic chains or to aromatic rings can be converted to the nitro $\left(\mathrm{NO}_{2}\right)$ group in a nitrating mixture, and this type of nitration is called ipsonitration. ${ }^{8-10} \mathrm{~A}$ key difference between ordinary nitration and ipso-nitration is described in Figure 1.

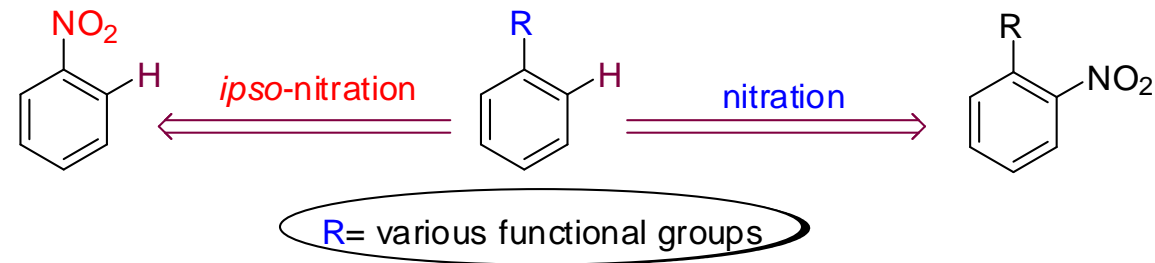

Figure 1. The key difference between nitration and ipso-nitration.

The ipso-nitration of organic compounds was initially developed with the use of nitric acid $\left(\mathrm{HNO}_{3}\right)$ or nitrating mixtures $\left(\mathrm{HNO}_{3} / \mathrm{AcOH}\right.$ or $\left.\mathrm{HNO}_{3} / \mathrm{H}_{2} \mathrm{SO}_{4}\right)$, approaches which are now referred to as traditional or classical methods. However, there are several problems with these traditional methods when it comes to forming regioselective nitro products. However, in spite of these problems, researchers have nonetheless tried, in the hope of obtaining selective nitro products, to refine these nitrating mixtures by increasing or decreasing the levels of nitric acid in the mixtures, by using catalysts or non-catalytic methods and various metal salts in making the mixtures, and by bypassing poor regioselectivity, low yields, and the formation of undesired by-products.

In recent years, several literature investigations have focused on such reported developments of ipsonitration reactions. In this review, we provide a general overview of recent advances and developments in ipso-nitration reactions that have been reported since the beginning of this century (i.e., in the period 20002015). 


\section{Developments in traditional ipso-nitration}

\section{1 ipso-Nitration of macromolecules (calixarenes)}

The most commonly used ipso-nitration reaction is one that is widely used in calixarene chemistry. ${ }^{11-13}$ If tertbutylcalix[4]arene is reacted with $63 \% \mathrm{HNO}_{3}$ in a mixture of dichloromethane (DCM) and glacial acetic acid at $15^{\circ} \mathrm{C}$, it was observed the formation of a selective mono ipso-nitrated compound in $85 \%$ yield (Scheme 1 ). In addition, if acetic anhydride is used instead of glacial acetic acid at $-10^{\circ} \mathrm{C}$, tert-butylcalix[4]arene generates dinitro products. ${ }^{14}$

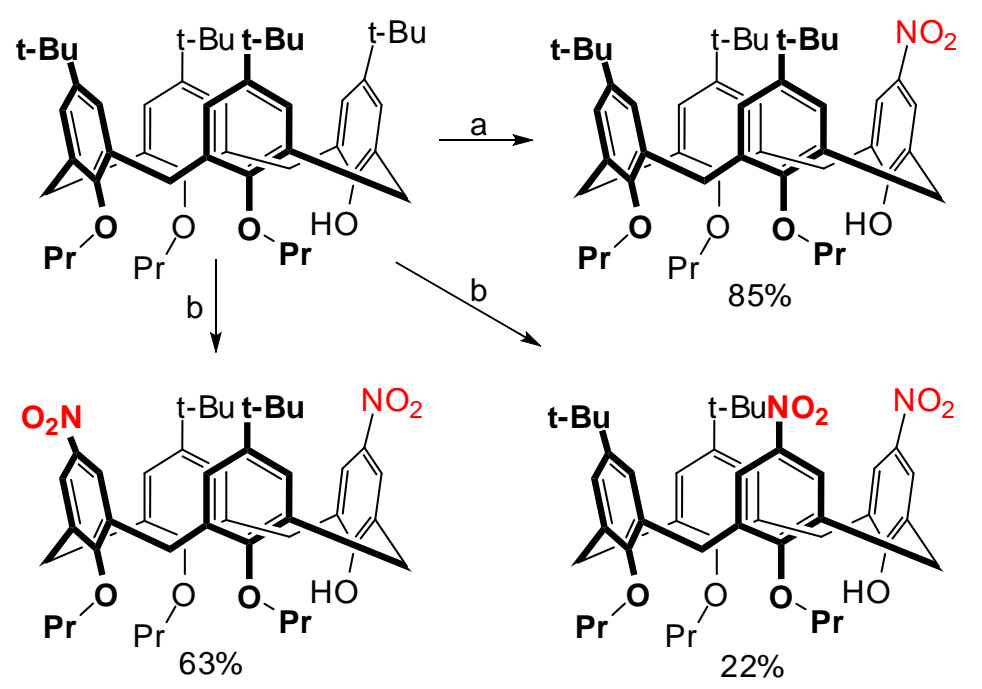

a) $63 \% \mathrm{HNO}_{3}, \mathrm{CH}_{3} \mathrm{COOH}, \mathrm{DCM},-15^{\circ} \mathrm{C}$

b) $63 \% \mathrm{HNO}_{3}, \mathrm{Ac}_{2} \mathrm{O}, \mathrm{DCM},-10^{\circ} \mathrm{C}$

Scheme 1. ipso-Nitration of tert-butylcalix[4]arene.

In 2005, Böhmer and colleagues reported the selective ipso-nitration of a tert-butylcalix[4]arene, ${ }^{15}$ following the by $O$-alkylation with $\omega$-bromoalkylphthalimides or $\omega$-bromonitriles (for $n=2 \mathrm{~N}$ - $(\beta$ hydroxyethylphthalimide, triphenylphosphine $\left./ \mathrm{Cs}_{2} \mathrm{CO}_{3}\right)$ to obtain 5,17-di-tert-butyl-11,23-dinitro-26,28diphthalimidoethoxycalix[4]arenes and the corresponding derivatives for $n=2$ or $4(n=2,3,4)$ in good yields (67-75\%) (Scheme 2). In this approach, $65 \% \mathrm{HNO}_{3}$ in DCM/acetic acid was used as the nitrating agent.

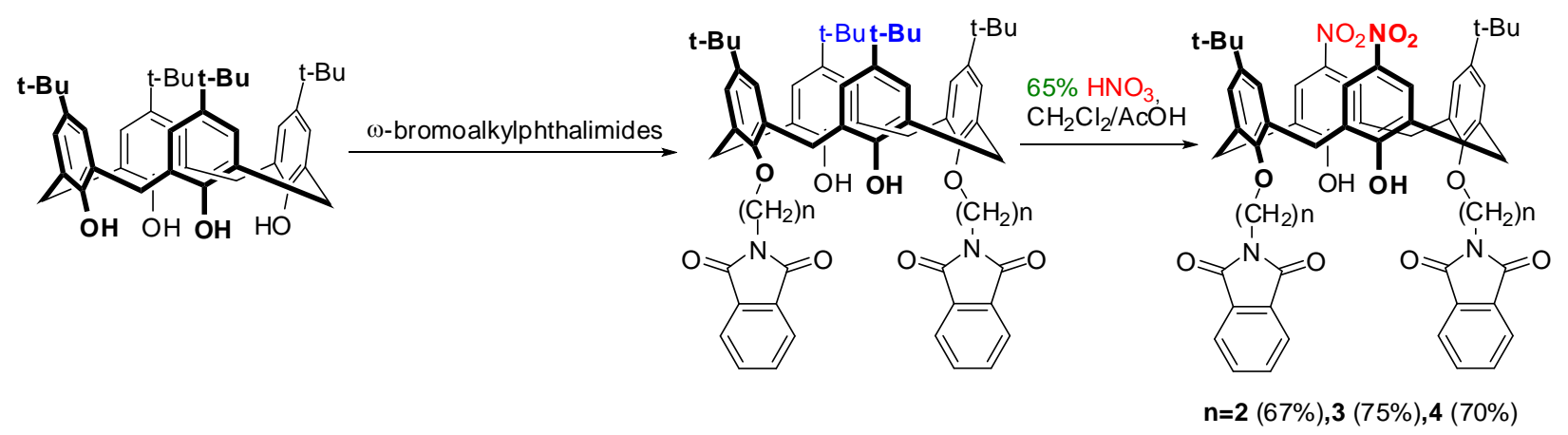

Scheme 2. Selective ipso-nitration of tert-butylcalix[4]arene. 
Hudecek et al. investigated a simple regioselective ipso-nitration of the nosyl-substituted calix[4]arenes. ${ }^{16}$ In their approach, they used $100 \% \mathrm{HNO}_{3}$ in an $\mathrm{AcOH} / \mathrm{DCM}$ mixture at room temperature. In the resulting ipsonitration of calix[4]arenes, selective ipso products were formed in yields of 99, 98, and 99\%, respectively (Scheme 3). In addition, the ${ }^{1} \mathrm{H}$ NMR spectrum of 11,23-di-tert-butyl-5,17-dinitro-25,27-bis( $p$ nitrobenzenesulfonyloxy)-26,28-dipropoxycalix[4]arene (cone) clearly proves the regioselective formation of a distal $p$-nitro-substituted product, where both $\mathrm{NO}_{2}$ groups are on the alkyloxylated rings.
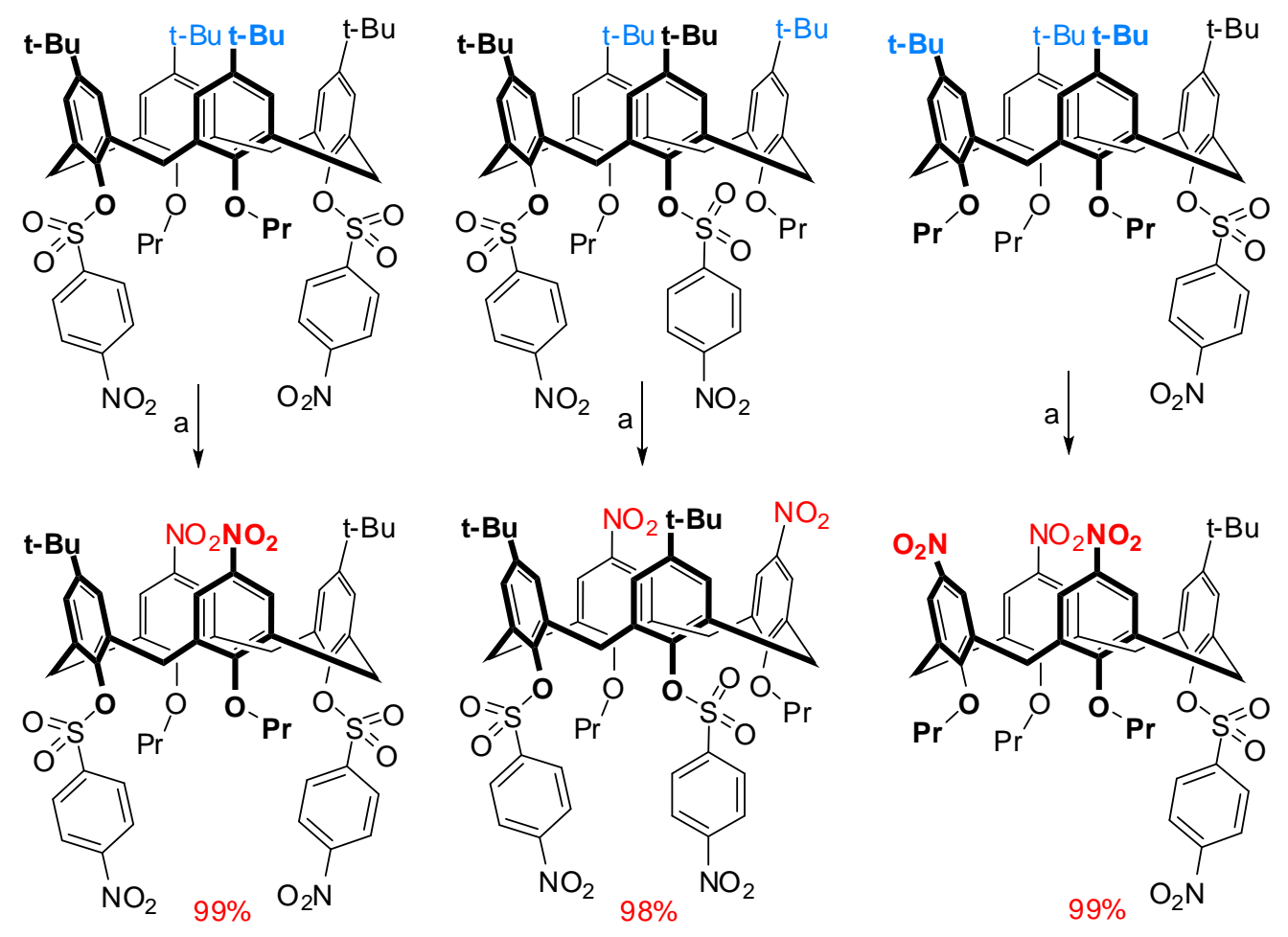

(a) $100 \% \mathrm{HNO}_{3} / \mathrm{AcOH} / \mathrm{DCM}, 0{ }^{\circ} \mathrm{C}$

Scheme 3. Regioselective ipso-nitration of calix[4]arenes.

Another selective ipso-nitration of calix[6]azacryptands involving tosyl, nosyl, and acetyl fragments, was also recently presented. ${ }^{17}$ In experiments following the traditional method, calix[6]arene derivatives were dissolved in DCM and then a mixture of fuming nitric acid/glacial acetic acid (1:1) at $0{ }^{\circ} \mathrm{C}$ was added, which finally resulted in the production of the selective nitro products in high yields (Scheme 4). The authors of this investigation utilized a classical approach to achieve an ipso-nitration reaction; however, they also observed that the electronic connection between the two rims is not the only factor that influences the selectivity. Rather, they noted that the conformational properties of the small rim part can also orient the selectivity of the ipso-nitration and influence the reaction rate. In order to achieve hexa-substitution, the reagent to substrate ratio (acid/calix) had to be increased ten-fold above that of the optimization condition. ${ }^{18}$ 


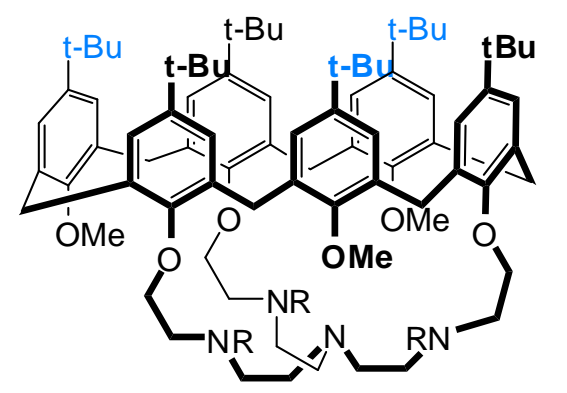

$\mathrm{HNO}_{3} / \mathrm{AcOH}(1: 1, \mathrm{v} / \mathrm{v})$, $\stackrel{\mathrm{DCM}, 0^{\circ} \mathrm{C} \text { then r.t., } 4-8 \mathrm{~h}}{\longrightarrow}$

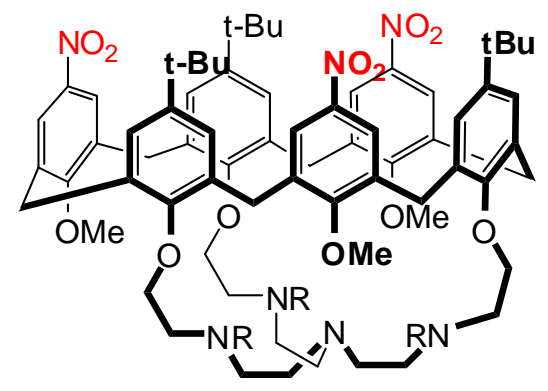

$R=T s(93 \%)$, Ns (95\%), Ac $83 \%$

Scheme 4. ipso-Nitration reactions of $\mathrm{N}$-sulfonamido and $\mathrm{N}$-acetamido calix[6]arenes.

Yamato et al. investigated the ipso-nitration of [ $\left.3_{n}\right]$ metacyclophanes (MCPs) with "cone" and "partialcone" conformations. ${ }^{19}$ The introduction of three nitro groups through the direct replacement of tert-butyl groups via ipso-nitration of 6,15,24-tri-tert-butyl-9,18,27-trimethoxy[3.3.3]MCP (1a) (Table 1) with fuming $\mathrm{HNO}_{3}$ for $0.5 \mathrm{~h}$ at room temperature formed 9,18,27-trimethoxy-6,15,24-trinitro[3.3.3]MCP (2a) in a 95\% yield. In contrast, if the ipso-nitration of $\mathrm{O}$-( $\mathrm{N}, \mathrm{N}$-diethylacetamide) derivative (1b) was attempted under these conditions, no reaction was observed.

Table 1. ipso-Nitration of $1 \mathrm{c}$

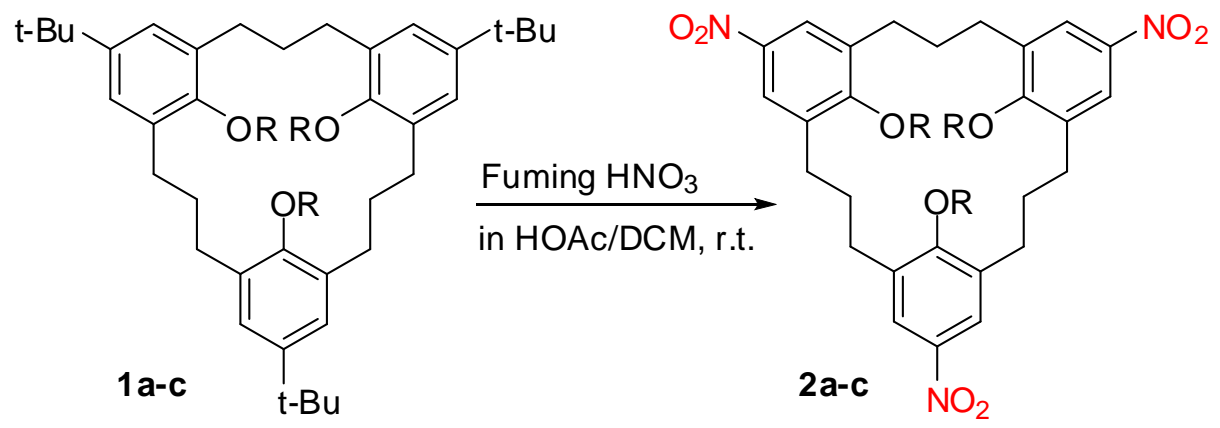

where for $\mathbf{a}, \mathrm{R}=\mathrm{Me} ; \mathbf{b}, \mathrm{R}=\mathrm{CH}_{2} \mathrm{CONEt}_{2}, \mathbf{c}, \mathrm{R}=\mathrm{CH}_{2} \mathrm{CO}_{2} \mathrm{Et}$
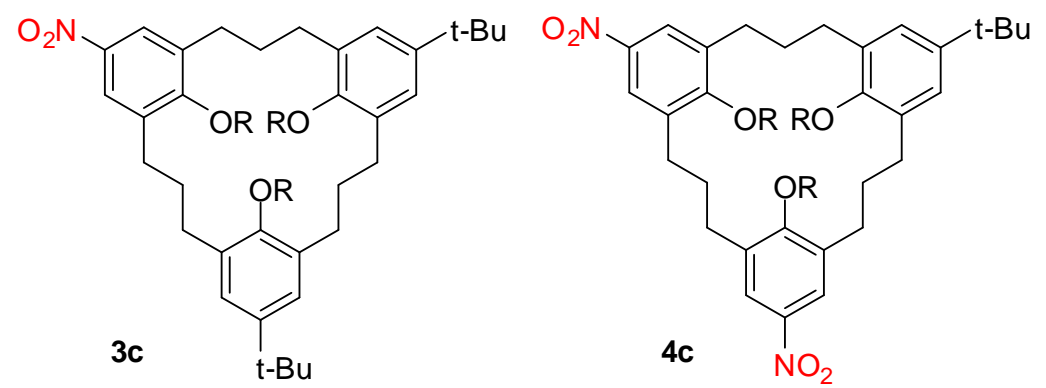

\begin{tabular}{clccccc}
\hline \multirow{2}{*}{ Entry } & \multirow{2}{*}{ Nitration reagents } & Time & \multicolumn{4}{c}{ Products (Yield \%) } \\
\cline { 5 - 7 } & & (h) & 3c & 4c & 2c \\
\hline 1 & $\mathrm{CuNO}_{3} / \mathrm{Ac}_{2} \mathrm{O}$ & 24 & 0 & 86 & 14 \\
2 & Fuming $\mathrm{HNO}_{3} / \mathrm{HOAc}$ & 0.5 & 0 & 75 & 25 \\
3 & Fuming $\mathrm{HNO}_{3} / \mathrm{HOAc}$ & 1 & 0 & 52 & 48 \\
4 & Fuming $\mathrm{HNO}_{3} / \mathrm{HOAc}$ & 2 & 0 & 0 & 100 \\
\hline
\end{tabular}


In addition, they used copper(II)nitrate in an acetic anhydride solution for the screening of cone-6,15,24tri-tert-butyl-9,18,27-tris[(ethoxycarbonyl)methoxy]-[3.3.3]MCP (cone-1c). After $24 \mathrm{~h}$, they obtained a mixture of the dinitration product cone-4c and the trinitration product cone-2c in 86 and $14 \%$ yields, respectively (Table 1). The mononitration product (cone-3c) was not obtained under any of the conditions they tested. ${ }^{19}$

The selective ipso-nitration of tert-butyl[2.2.2]MCP through the use of fuming nitric acid or copper nitrate was reported in 2011 by Sawada et al. ${ }^{20}$ As detailed in that report, when 2,2',9,9'-tetra-t-butyl-5a,10b-dihydro$[1,1](4,7)$ benzofuro[2,3-b]benzofuranophane interacted with fuming nitric acid, it was observed formation of selective dinitro product, if copper nitrate was used as nitrating agent, it was obtained tetranitro compound in $75 \%$ yield (Scheme 5 ). With regard to selective dinitro products, a ${ }^{1} \mathrm{H}$ NMR signal for tert-butyl protons was observed at $1.26 \mathrm{ppm}$ with an intensity ratio of 18 protons. This indicates that two tert-butyl groups are substituted by two nitro groups.
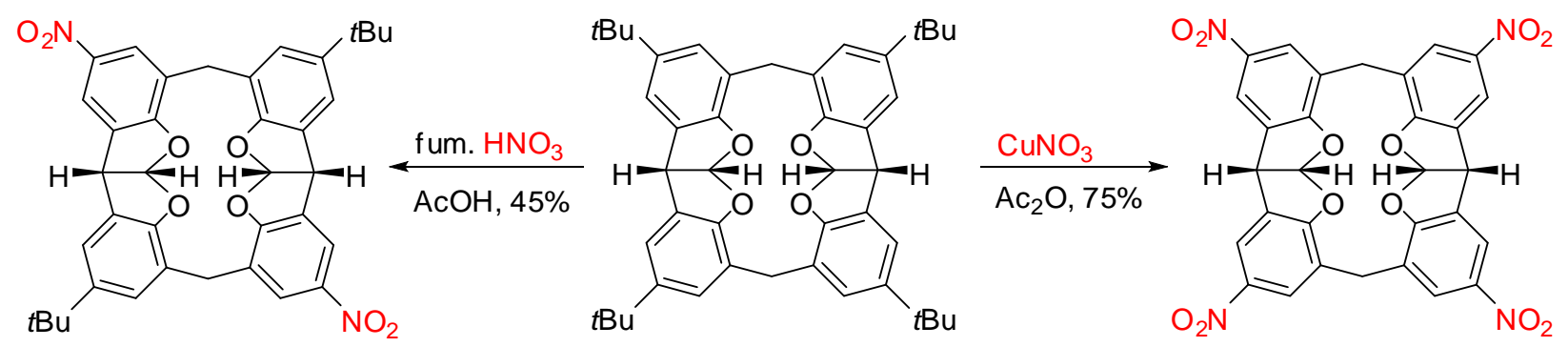

Scheme 5. ipso-Nitration of tert-butyl[2.2.2]MCP.

Obviously, the nature of the various substituents $(R)$ plays a key role in the determination of the nitration positions in the ipso-nitration of calixarenes in traditional methods, when used nitric acid as nitrating agent. Redon et al. explained a possible mechanism for this in their report. ${ }^{21}$ In brief, the mechanism is related to the presence of a protonable site at the $y$-position of the phenolic oxygen atom. Due to the basic character of calixarenes, all of their nitrogenous arms must be protonated under strongly acidic reaction conditions. This protonated nitrogen group is in an ideal position for hydrogen bonding to the phenolic oxygen atom, and thus deactivating the whole aromatic cycle toward electrophilic attack by removing the electron density (Scheme 6).

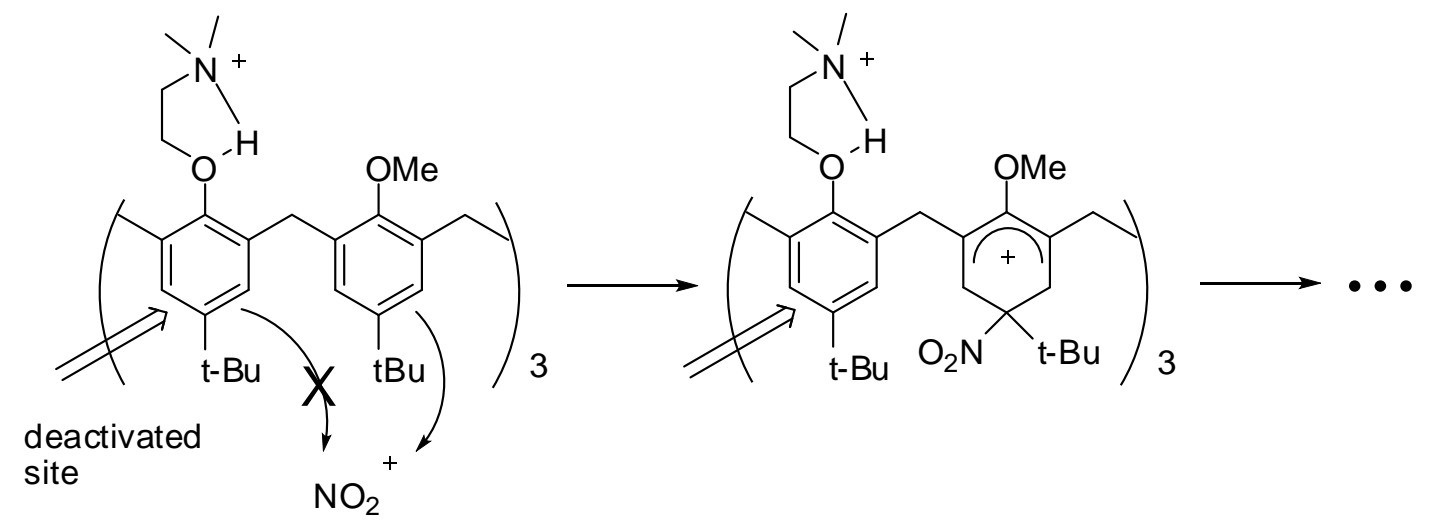

Scheme 6. Proposed mechanism for the selective ipso-nitration with calix[6]arenes.

In general, a more suitable condition or nitrating agent for the conversion of calixarenes in good yields into nitrocalixarenes is to use nitric acid in acetic acid at lower (i.e. 0-5 ${ }^{\circ} \mathrm{C}$ ) temperatures. Chawla and co- 
workers $^{22}$ showed this by applying a comparative analysis to a variety of reaction conditions (Table 2). As indicated, ipso-nitration with acetic anhydride/nitric acid ensures a good yield of $p$-nitrocalix[n]arenes; however, a similar reaction with $p$-tert-butylcalix[n]arenes leads to a mixture from which nitrocalix[n]arenes can only be separated in lower yields due to acetylation. Similarly, the use of CAN/acetic acid also produces lower yields due to the oxidation of substrates.

Table 2. ipso-Nitration of $p$-tert-butylcalix[ $n]$ arenes using different nitrating reagents

\begin{tabular}{ccccc}
\hline Calix[n]arene & Nitrating mixture & $\begin{array}{c}\text { Temperature } \\
\left({ }^{\circ} \mathrm{C}\right)\end{array}$ & $\begin{array}{c}\text { Time } \\
(\mathrm{h})\end{array}$ & Yield (\%) \\
\hline Calix[4] & $\mathrm{CH}_{3} \mathrm{COOH} / \mathrm{HNO}_{3}$ & $0-5$ & 4 & 76 \\
Calix[6] & $\mathrm{CH}_{3} \mathrm{COOH} / \mathrm{HNO}_{3}$ & $0-5$ & 4 & 79 \\
Calix[8] & $\mathrm{CH}_{3} \mathrm{COOH} / \mathrm{HNO}_{3}$ & $0-5$ & 4 & 70 \\
Calix[4] & $\mathrm{Ac}_{2} \mathrm{O} / \mathrm{HNO}_{3}$ & 0 & 5 & 75 \\
Calix[6] & $\mathrm{Ac}_{2} \mathrm{O} / \mathrm{HNO}_{3}$ & 0 & 5 & 78 \\
Calix[8] & $\mathrm{Ac}_{2} \mathrm{O} / \mathrm{HNO}_{3}$ & 0 & 5 & 76 \\
Calix[4] & $\mathrm{CAN} /$ acetone/AcOH & Reflux & 8 & 50 \\
Calix[6] & $\mathrm{CAN} /$ acetone/AcOH & Reflux & 8 & 55 \\
Calix[8] & $\mathrm{CAN} /$ acetone/AcOH & Reflux & 8 & 55 \\
\hline
\end{tabular}

\section{2 ipso-Nitration of heterocycles}

Our own research group reported for the first time that, depending on the presence of substituents in positions 2 and 3 of the pyrimidine and thiophene rings, ipso-nitration or oxidation proceeds in various directions, either by the electrophilic ipso-substitution of methyl groups at C-5 by nitro groups or by their oxidation to carboxyl groups with the formation of the corresponding 5-carboxy derivatives (Scheme 7). ${ }^{23-26}$ This research also revealed that, in the absence of a substituent in position 3, the electrophilic ipsosubstitution of the methyl group by a nitro group with the formation of a 5-nitro derivative would take place. Thus, we found that, when the interaction of the compounds with electron-donating groups at $\mathrm{N}-3$ position of the thienopyrimidine molecule was conducted with a nitrating mixture $\left(\mathrm{HNO}_{3} / \mathrm{H}_{2} \mathrm{SO}_{4}\right.$ at $\left.0-5{ }^{\circ} \mathrm{C}\right)$, instead of the ipso-nitration of methyl groups at $\mathrm{C}-5$ the reaction proceeded in an unexpected direction, i.e., there was oxidation of the methyl groups.

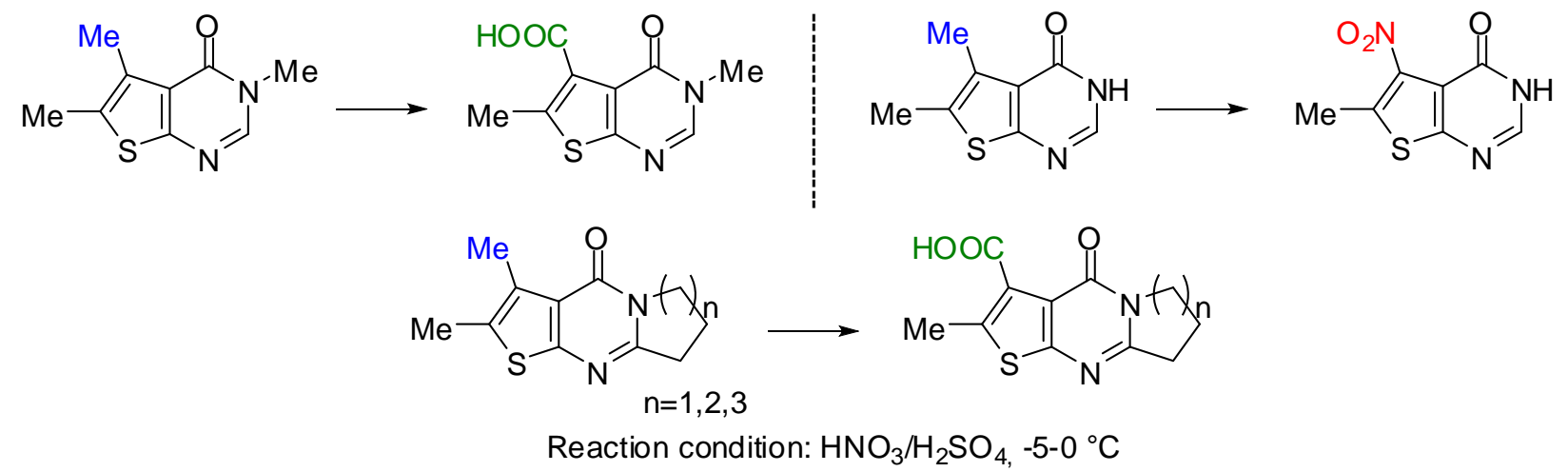

Scheme 7. ipso-Nitration of thienopyrimidines. 


\subsection{Cerium (IV) ammonium nitrate (CAN) as nitrating agent}

Messere et al. described the ipso-nitration reaction of substituted cinnamic acids with cerium (IV) ammonium nitrate (CAN) with the support of silica in a solid-phase approach. ${ }^{27}$ In their work, substituted-hydroxycinnamic acids were selected as substrates, and among them, only 4-hydroxycinnamic acid, when reacted under the above conditions for $15 \mathrm{~min}$. in methanol, produced an ipso-nitration product in a yield as high as $34 \%$. It was observed, that during the reaction process formed nitration products (57\%) and 4-hydroxycinnamaldehyde $(4 \%)$ as a side product in low yields (Scheme 8). When cinnamic acid was reacted with $\mathrm{CAN} / \mathrm{SiO}_{2}$, it failed to produce any ipso-nitration product; rather, the retention of the carboxylic functional group was observed.

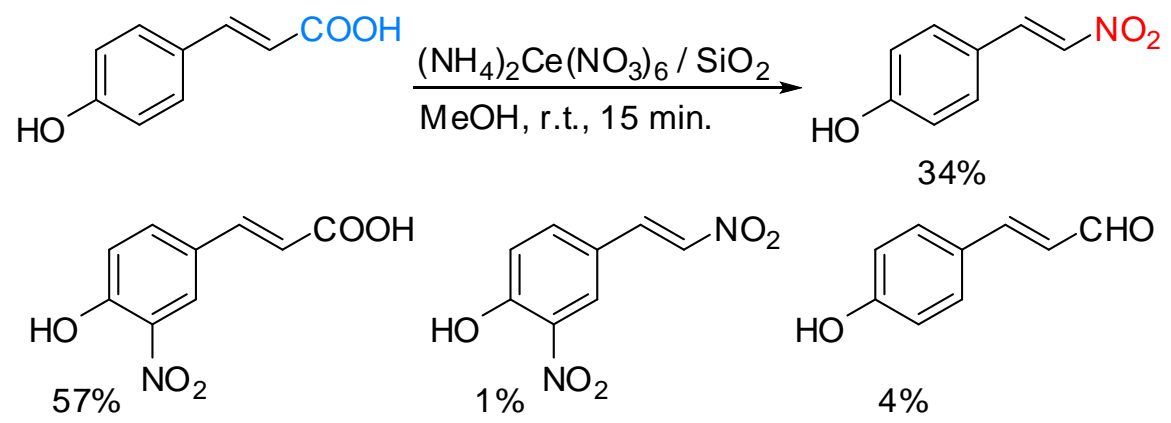

Scheme 8. ipso-Nitration of 4-hydroxycinnamic acid with $\mathrm{CAN} / \mathrm{SiO}_{2}$.

On the other hand, the ipso-nitration of a vinyl carboxyl group with $\mathrm{HNO}_{3}$ is unusual. Probably, the ipsonitrated product and 4-hydroxycinnamic acid go through hydrolysis and oxidation to yield benzoic acid, which is then susceptible to ipso-nitration with decarboxylation. ${ }^{28,29}$

LaLonde and colleagues discovered that the use of CAN in acetic acid/water (9:1) results in the conversion of $(3 \mathrm{a} R, 4 S, 9 \mathrm{a} R)$ and $(3 \mathrm{a} R, 4 S, 9 \mathrm{a} S)$ tetrahydrofurans into ipso-products via simultaneous ipso-nitration and oxidation through the opening of the B-ring of the tetrahydrofurans (Scheme 9). ${ }^{30}$

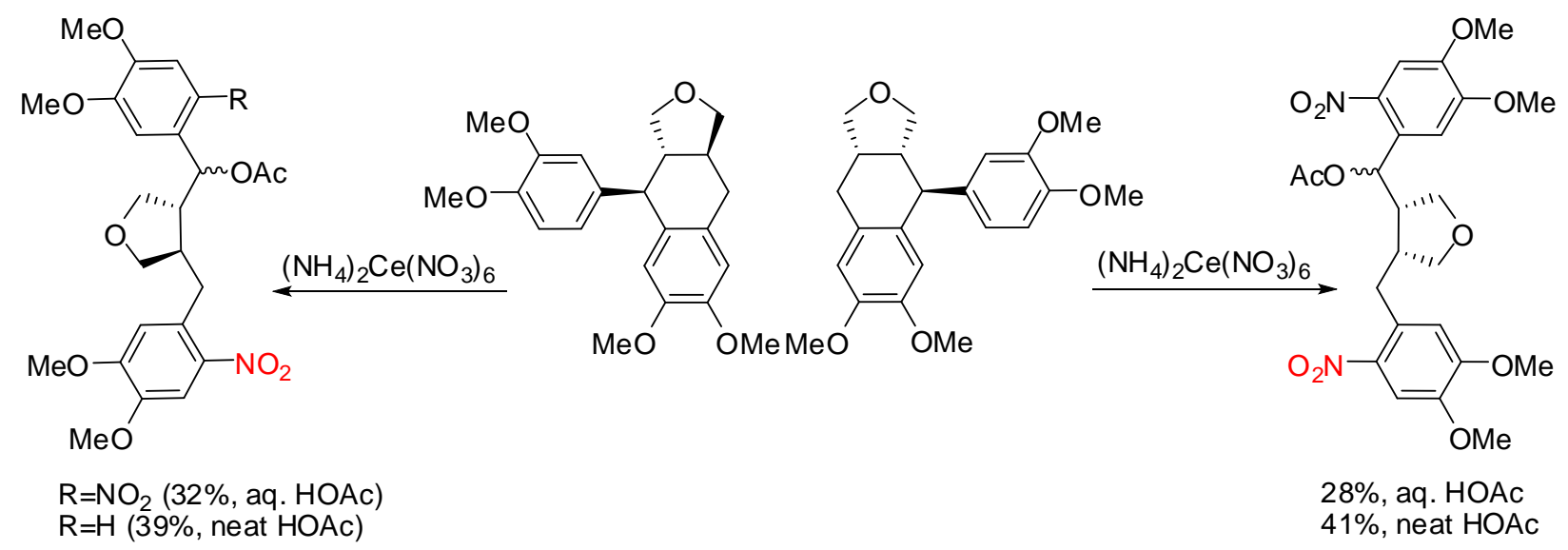

Scheme 9. ipso-Nitration of $(3 \mathrm{a} R, 4 S, 9 \mathrm{a} R)$ and $(3 \mathrm{a} R, 4 S, 9 \mathrm{a} S)$ tetrahydrofurans with CAN

When the $(3 \mathrm{a} R, 4 S, 9 \mathrm{a} S)$ derivative was treated with CAN in neat acetic acid, the yield of the final product rose to $41 \%$, whereas the treatment of $(3 \mathrm{a} R, 4 S, 9 \mathrm{a} R)$ derivative under the same conditions resulted in a similar yield of mononitroburseran (39\%) favoring one of two diastereomeric acetates. 


\section{Modern Approaches to ipso-Nitration}

\section{1 ipso-Nitration of carboxylic groups}

It has previously been proven that various silver salts can be employed as catalysts for decarboxylative carboncarbon, carbon-silicon, carbon-oxygen, carbon-boron, carbon-sulfur, carbon-phosphorus, and carbon-halogen bond-forming reactions. Proceeding from these facts, Natarajan et al. described a novel and efficient approach for the ipso-nitration of a broad range of carboxylic acids with nitronium tetrafluoroborate $\left(\mathrm{NO}_{2} \mathrm{BF}_{4}\right)$ as a nitrating agent and silver carbonate $\left(\mathrm{Ag}_{2} \mathrm{CO}_{3}\right)$ as a decarboxylation reagent in dimethylacetamide (DMA) (Table 3). ${ }^{31}$

Table 3. ipso-Nitration of alkyl and aryl carboxylic acids

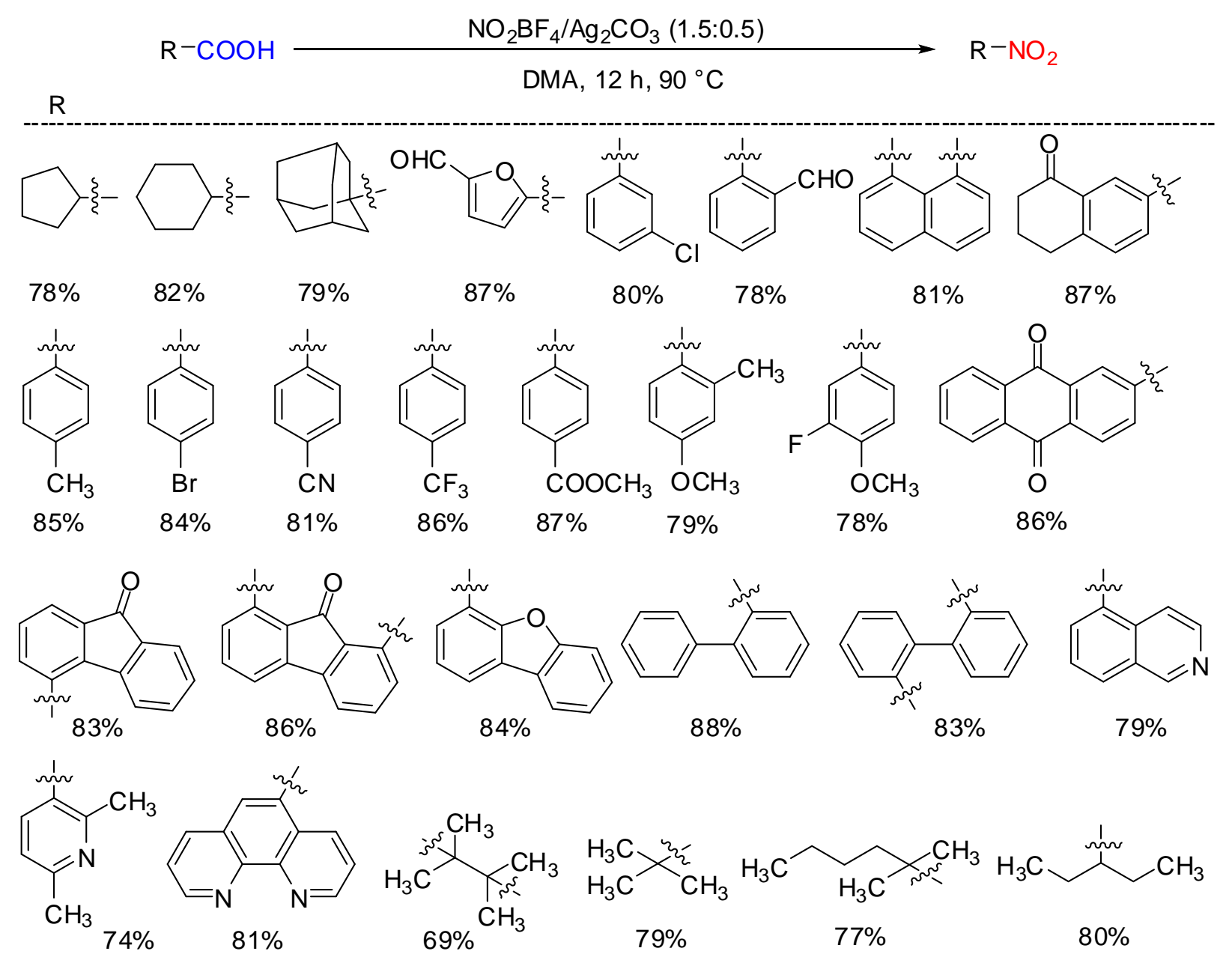

Reactions in various anhydrous solvents including acetonitrile, chloroform, DCM, dichloroethane, DMA, tetrahydrofuran, and tetrachloroethane suggested that anhydrous DMA was the best medium for the ipsonitration of aliphatic and aromatic carboxylic acids. Furthermore, this research group demonstrated the generality of this new protocol by applying it to a series of electronically diversified aliphatic and aromatic carboxylic acids (Table 3). In those reactions, aryl-/heteroaryl-/polyaryl carboxylic acids with electron donating $\left(\mathrm{CH}_{3}, \mathrm{OCH}_{3}, \mathrm{C}_{6} \mathrm{H}_{5}\right)$ and withdrawing $\left(\mathrm{F}, \mathrm{Cl}, \mathrm{Br}, \mathrm{CN}, \mathrm{CF}_{3}, \mathrm{CHO}, \mathrm{COOCH}_{3}\right)$ groups afforded moderate to good yields 
of corresponding nitroarenes. The reactions were all complete within $12 \mathrm{~h}$, affording the desired products in $74-88 \%$ yields.

Thus, the proposed mechanism (Scheme 10) starts with an anion exchange at the silver center to produce the metal carboxylate, which in turn provides an arylmetal species through the extrusion of carbon dioxide. A subsequent reaction with nitronium ion results in the formation of the desired nitro compound, leaving silver tetrafluoroborate as a byproduct. It is noteworthy to mention that, in the absence of $\mathrm{NO}_{2} \mathrm{BF}_{4}$, only the decarboxylated compound was detected, which indicates the formation of an aryl-silver species as an intermediate.

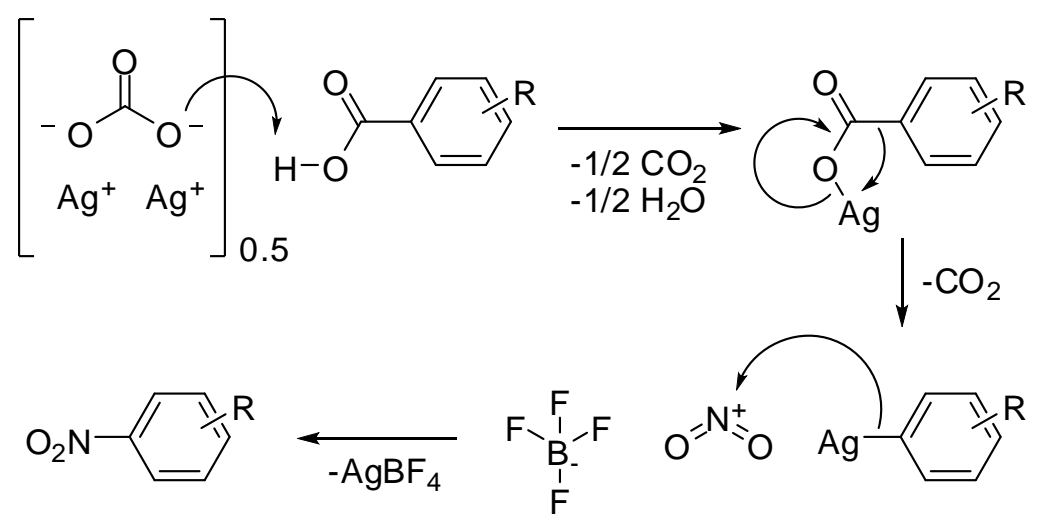

Scheme 10. Proposed mechanism for the decarboxylative ipso-nitration.

Table 4. Effect of copper salts and nitrating agents on ipso-nitration<smiles>CCn1cc(C(=O)O)c(=O)c2cc(F)c(Cl)cc21</smiles>

\begin{tabular}{cccccccccc}
\hline Entry & $\begin{array}{c}\text { Lewis } \\
\text { acid }\end{array}$ & $\begin{array}{c}\text { Amount } \\
\text { (mol\%) }\end{array}$ & $\mathrm{MNO}_{3}$ & $\begin{array}{c}\text { Yield } \\
(\%)\end{array}$ & Entry & $\begin{array}{c}\text { Lewis } \\
\text { acid }\end{array}$ & $\begin{array}{c}\text { Amount } \\
(\mathrm{mol} \%)\end{array}$ & $\mathrm{MNO}_{3}$ & $\begin{array}{c}\text { Yield } \\
(\%)\end{array}$ \\
\hline 1 & $\mathrm{Cu}(\mathrm{OAc})_{2}$ & 40 & $\mathrm{AgNO}_{3}$ & 65 & 6 & $\mathrm{Cu}(\mathrm{OAc})_{2}$ & 60 & $\mathrm{La}\left(\mathrm{NO}_{3}\right)_{3}$ & 66 \\
2 & $\mathrm{Cu}(\mathrm{OAc})_{2}$ & 50 & $\mathrm{AgNO}_{3}$ & 87 & 7 & $\mathrm{Cu}(\mathrm{OAc})_{2}$ & 60 & $\mathrm{Ca}\left(\mathrm{NO}_{3}\right)_{2}$ & 59 \\
3 & $\mathrm{Cu}(\mathrm{OAc})_{2}$ & 60 & $\mathrm{AgNO}_{3}$ & 92 & 8 & $\mathrm{Cu}(\mathrm{OAc})_{2}$ & 100 & $\mathrm{AgNO}_{3}$ & 90 \\
4 & $\mathrm{CuOAc}$ & 60 & $\mathrm{AgNO}_{3}$ & 72 & 9 & - & & $\mathrm{AgNO}_{3}$ & - \\
5 & $\mathrm{Cu}(\mathrm{OAc})_{2}$ & 60 & $\mathrm{NaNO}_{3}$ & 72 & & & & $\mathrm{La}\left(\mathrm{NO}_{3}\right)_{3}$ & 66 \\
\hline
\end{tabular}

In 2015, Azad et al. developed an efficient, cost-effective, and green methodology for the ipso-nitration of 3-carboxy-4-quinolones via the quantitative use of copper acetate and silver nitrate in water. ${ }^{32}$ The effect of $^{-}$ the metal nitrating agent, catalyst, and solvent was investigated under the conditions of an open atmosphere and a temperature of $100^{\circ} \mathrm{C}$ over $24 \mathrm{~h}$, with 7-chloro-1-ethyl-6-fluoro-4-oxo-1,4-dihydroquinoline-3-carboxylic acid used as the substrate. Copper (II) acetate was selected for the condition screening with AgNO3 as a nitrating agent, and water as the solvent. The results indicated that 60 mol\% $\mathrm{Cu}(\mathrm{OAc})_{2}$ converted the substrate 
into a nitro product at $92 \%$ yield (Table 4). When $\mathrm{NaNO}_{3}$ and $\mathrm{La}\left(\mathrm{NO}_{3}\right)_{3}$ were each used as the nitrating agent, the nitro products were formed at yields of 72 and 66\%, respectively. The reaction did not proceed at all if no catalysts were used. Copper (I) was also effective, albeit affording lower yields.

Further, the same researchers used dihalo $(\mathrm{F} / \mathrm{Cl}, \mathrm{F} / \mathrm{F}$, and $\mathrm{Cl} / \mathrm{Cl})$ quinolones related with various alkyl groups at the N1 position for ipso-nitration. Ipso products were obtained in yields $80-96 \%$, when the relevant reactions were allowed proceeded for 12-20 hrs (Table 5).

Table 5. ipso-Nitration of dihalo-3-carboxy-4-quinolones

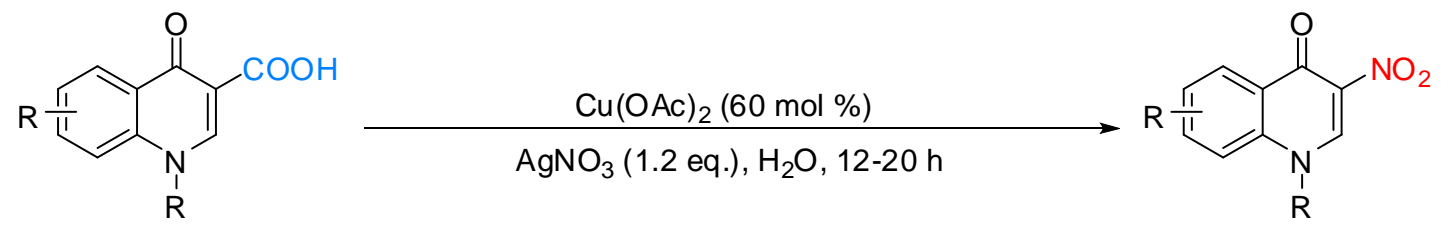<smiles>CCCCCCn1cc([N+](=O)[O-])c(=O)c2cc(F)c([N+](=O)[O-])cc21</smiles><smiles></smiles>

$82 \%$

$81 \%$ $82 \%$ $89 \%$<smiles>CCCCn1cc([N+](=O)[O-])c(=O)c2cc(Cl)c([N+](=O)[O-])cc21</smiles><smiles>CC(C)n1cc([N+](=O)[O-])c(=O)c2cc(Cl)c(Cl)cc21</smiles><smiles></smiles>

\section{2 ipso-Nitration of halogens}

In order to circumvent the need for a phase transfer catalyst, Lakshmi Kantam and colleagues studied the copper catalyzed ipso-nitration of iodoarenes, bromoarenes, and heterocyclic haloarenes under ligand-free conditions. ${ }^{33}$ In their experiments, 4-bromothioanisole was initially selected as the substrate for performing the optimization reaction, while 25 mol\% copper salts and 3 equiv of $\mathrm{KNO}_{2}$ were selected as the catalysts and nucleophile, respectively. Among the various optimization studies for the ipso-nitration of 4-bromothioanisole, the most promising result (an $84 \%$ yield) was obtained using 25 mol\% of $\mathrm{Cu}\left(\mathrm{OSO}_{2} \mathrm{CF}_{3}\right)_{2}$ and 3 equiv of $\mathrm{KNO}_{2}$ in $0.6 \mathrm{~mL}$ of DMSO at $130^{\circ} \mathrm{C}$.

A wide variety of electron-rich and electron-deficient iodoarenes and bromoarenes were then studied for ipso-nitration after the optimization. It was observed that a lot of electron-rich haloarenes reacted smoothly, irrespective of the nature and orientation of the functional groups present, to produce the nitro products in good yields (Table 6). It is important to note that several functional groups, including $\mathrm{NO}_{2}, \mathrm{CHO}, \mathrm{CN}, \mathrm{COPh}$, $\mathrm{NMe}_{2}, \mathrm{OCH}_{2} \mathrm{Ph}, \mathrm{OMe}, \mathrm{SMe}, \mathrm{Ph}$, and $\mathrm{Me}$, were tolerated in this condition, except for 4-bromoaniline and 4iodophenol. In addition, this method could be carried out for the ipso-nitration of heterocycles such as 2- 
bromopyridine, 3-bromoquinoline, 6-bromoquinoline, 1-(4-iodophenyl)-1H-pyrrole, and 4-(4bromophenyl)pyrimidine.

Table 6. Copper catalyzed ipso-nitration of haloarenes

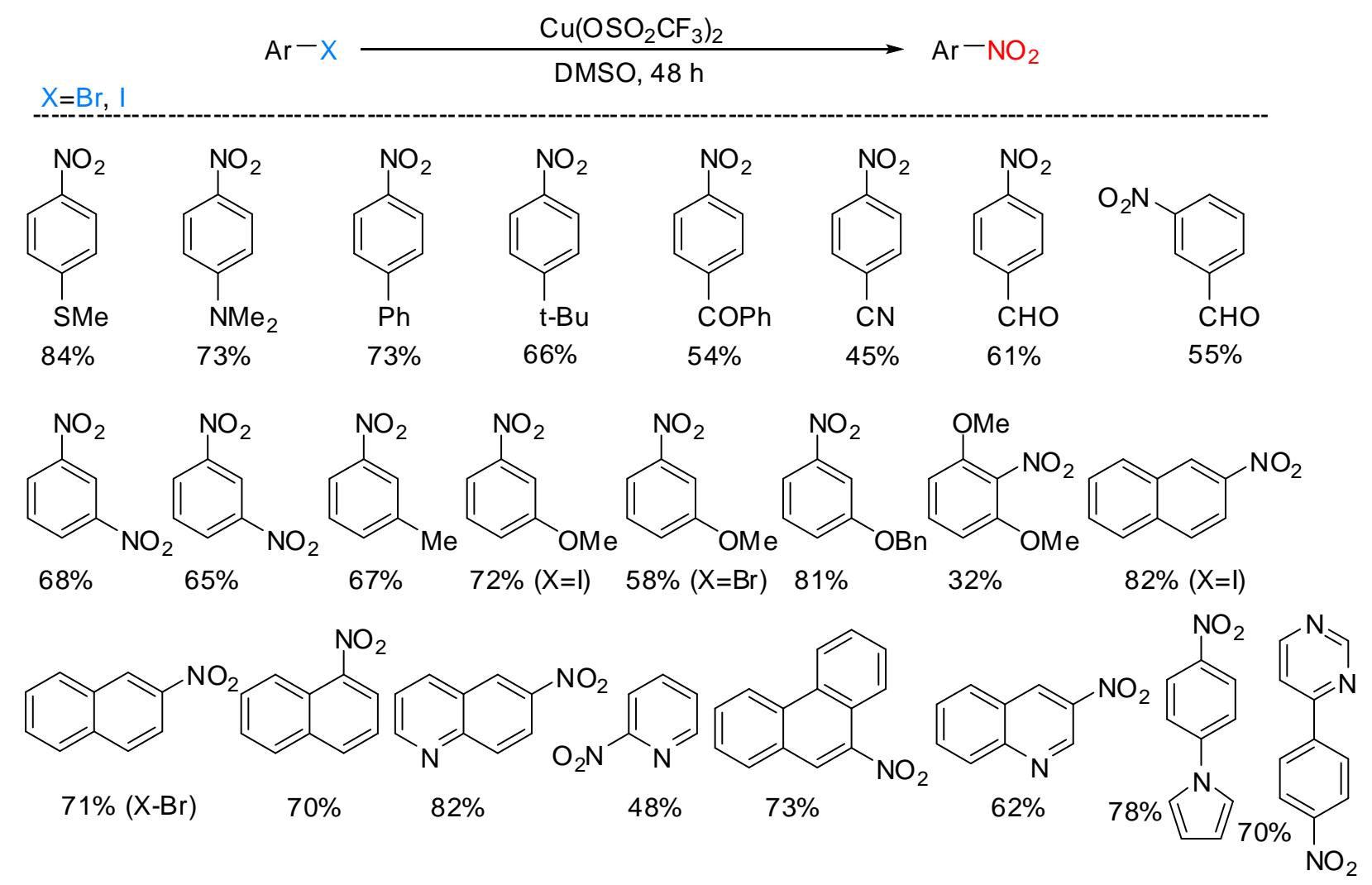

\section{3 ipso-Nitration of arylboronic acids}

Surya Prakash and co-workers have reported a simple, convenient, and mild method for the ipso-nitration of arylboronic acids using inorganic nitrate salt and chlorotrimethylsilane (TMSCl) (Table 7). ${ }^{34}$ In this type of ipsonitration, 2-10\% nitrochlorination was observed in certain cases. It was found that when $\mathrm{AgNO}_{3}$ was used instead of $\mathrm{NH}_{4} \mathrm{NO}_{3}$ as the nitrate salt, the extent of chlorination was significantly decreased. In addition, it was investigated the effect of various nitrate salts and solvents on ipso-nitration reactions and it was observed that $\mathrm{AgNO}_{3}$ and $\mathrm{DCM}$ provided the best results, respectively.

$\mathrm{TMSCl}$ reacts with nitrate salts to generate $\mathrm{TMS}-\mathrm{O}-\mathrm{NO}_{2}$ species. The dinitro product, however, was not observed in any such reactions; it is likely that there exists a prominent electronic interaction between the boronic acid group and the intermediate active nitrating agent TMS-O- $\mathrm{NO}_{2}$ species via the boron and the siloxy group due to the high oxophilicity of boron (Scheme 11). This would help the nitration to occur at the ipso position. $\mathrm{TMS}-\mathrm{O}-\mathrm{NO}_{2}$ can then undergo further reaction with excess $\mathrm{TMSCl}$ to produce hexamethyldisiloxane and nitryl chloride, which can also act as the nitrating species. For the generation of nitryl chloride, an excess of $\mathrm{TMSCl}$ is required, but it was observed that phenylboronic acid can undergo nitration completely with 1 equiv of TMSCl. Generally, this reaction takes $72 \mathrm{~h}$ for completion. It should be noted, that this method was found more selective than the method in which Crivello's reagent ${ }^{35}$ were used to provide the ipso-nitration products in moderate to high yields. Another significant feature of this method is the complete absence of dinitro product. 
Table 7. ipso-Nitration of arylboronic acids using $\mathrm{TMSCl} /$ nitrate salts

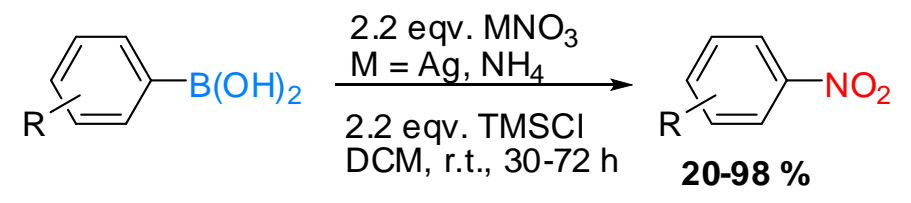

Entry

$\mathrm{x}\left(\mathrm{CH}_{3}\right)_{3} \mathrm{Si}-\mathrm{Cl}+\mathrm{M}\left(\mathrm{NO}_{3}\right)_{x} \longrightarrow \underbrace{\mathrm{x}\left(\mathrm{CH}_{3}\right)_{3} \mathrm{Si}-\mathrm{O}-\mathrm{NO}_{2}}_{\text {active nitrating species }}+\mathrm{MCl}_{\mathrm{x}} \stackrel{\mathrm{x}\left(\mathrm{CH}_{3}\right)_{3} \mathrm{SiCl}}{\longrightarrow} \times\left(\mathrm{CH}_{3}\right)_{3} \mathrm{Si}-\mathrm{O}-\mathrm{Si}\left(\mathrm{CH}_{3}\right)_{3}+x \mathrm{NO}_{2} \mathrm{Cl}$
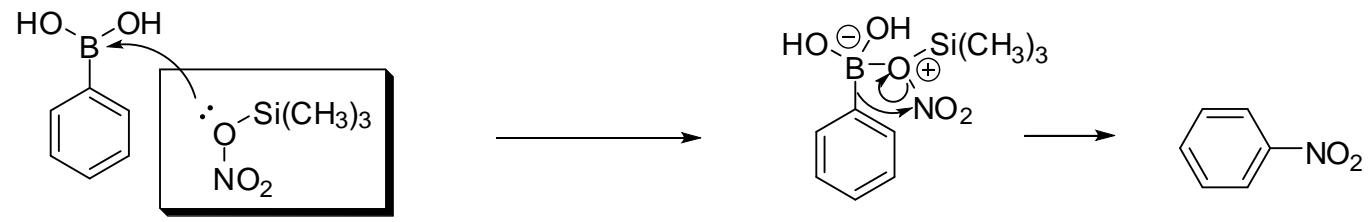

Scheme 11. Proposed mechanism for ipso-nitration of arylboronic acid. 
Based on this result, the same group studied the interaction of arylboronic acids with a $\mathrm{NaNO}_{2}-\mathrm{TMSCl}$ system, and ultimately observed ipso-nitrosation reactions in most cases. ${ }^{36}$ Initially, 4-methoxyphenylboronic acid was selected for optimization, and was then added to a stirred mixture of $\mathrm{NaNO}_{2}$ (2.2 equiv) and TMSCl (2.2 equiv) in anhydrous dichloromethane under argon at room temperature for $72 \mathrm{~h}$. However, as the initial results proved to be unsuccessful, the conditions of an open-air atmosphere and the addition of 0.5 equiv of water were applied for a reaction time of $3 \mathrm{~h}$., all of which appeared to be suitable conditions for the reaction. The mechanism of the ipso-nitrosation reaction of arylboronic acids with sodium nitrite and TMSCI (Scheme 12) is similar to the mechanism illustrated above in Scheme 12, the key difference being the formation of TMSO-NO species instead of TMS-O-NO 2 species.

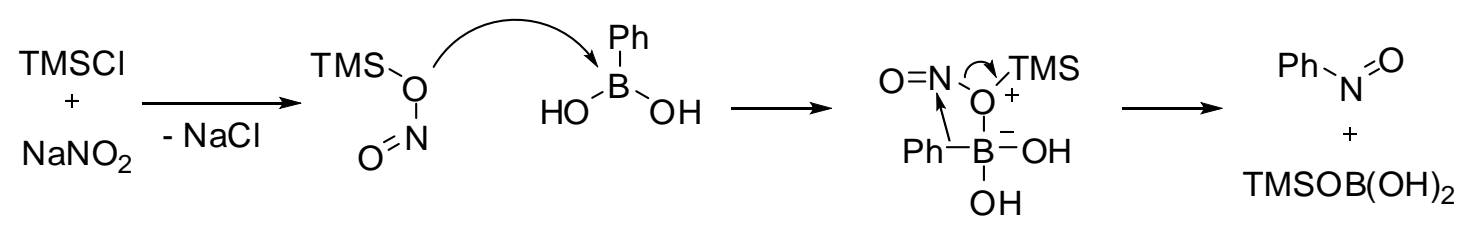

Scheme 12. Proposed mechanism of ipso-nitrosation of phenylboronic acid with $\mathrm{NaNO}_{2}$ and TMSCl.

If arylboronic acids with various substituents in the aromatic portion react under the above conditions, ipso-nitrosation and ipso-nitration products in different ratios can be observed as the final resulting compounds (Table 8). It was observed, for example, that 4-alkoxy- and 4-phenoxyphenylboronic acids underwent the reaction smoothly to produce the corresponding nitrosoarenes in both high yields and good chemoselectivities.

Table 8. ipso-Nitrosation of arylboronic acids

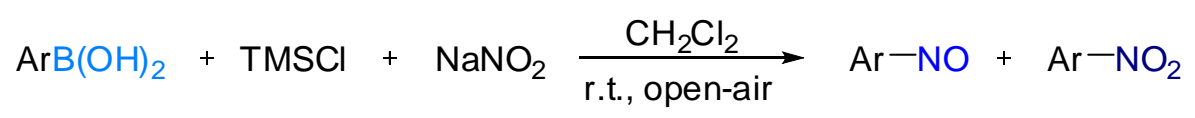

\begin{tabular}{|c|c|c|c|c|c|}
\hline \multirow{2}{*}{ Entry } & \multirow{2}{*}{ Substrate } & \multirow{2}{*}{$\begin{array}{c}\text { Conversion } \\
(\%)\end{array}$} & \multirow{2}{*}{$\begin{array}{l}\text { Time } \\
\text { (h) }\end{array}$} & \multicolumn{2}{|c|}{ Yield (\%) } \\
\hline & & & & $\mathrm{Ar}-\mathrm{NO}$ & $\mathrm{Ar}-\mathrm{NO}_{2}$ \\
\hline 1 & $(\mathrm{OH})_{2}$ & $>99$ & 12 & 2 & 97 \\
\hline 2 & $\mathrm{~B}(\mathrm{OH})_{2}$ & $>99$ & 12 & 59 & 41 \\
\hline 3 & $\mathrm{~B}(\mathrm{OH})_{2}$ & 0 & 12 & - & - \\
\hline 4 & $-\mathrm{B}(\mathrm{OH})_{2}$ & $>99$ & 12 & 10 & 85 \\
\hline 5 & $-\mathrm{B}(\mathrm{OH})_{2}$ & $>99$ & 12 & 14 & 65 \\
\hline 6 & & $>99$ & 12 & 28 & 64 \\
\hline
\end{tabular}


Table 8. Continued

\begin{tabular}{|c|c|c|c|c|c|}
\hline \multirow{2}{*}{ Entry } & \multirow{2}{*}{ Substrate } & \multirow{2}{*}{$\begin{array}{c}\text { Conversion } \\
(\%)\end{array}$} & \multirow{2}{*}{$\begin{array}{l}\text { Time } \\
\text { (h) }\end{array}$} & \multicolumn{2}{|c|}{ Yield (\%) } \\
\hline & & & & $\mathrm{Ar}-\mathrm{NO}$ & $\mathrm{Ar}-\mathrm{NO}_{2}$ \\
\hline 7 & 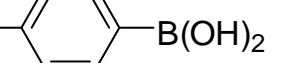 & 0 & 12 & 0 & 0 \\
\hline 8 & & $>99$ & 12 & 0 & 95 \\
\hline 9 & $-\mathrm{B}(\mathrm{OH})_{2}$ & $>99$ & 12 & 96 & 1 \\
\hline 10 & $-\mathrm{B}(\mathrm{OH})_{2}$ & $>99$ & 2 & 87 & 12 \\
\hline 11 & $-\mathrm{B}(\mathrm{OH})_{2}$ & $>99$ & 2 & 94 & 1 \\
\hline 12 & $-\mathrm{B}(\mathrm{OH})_{2}$ & $>99$ & 4 & 60 & 36 \\
\hline 13 & & $>99$ & 2 & 12 & 7 \\
\hline 14 & & $>99$ & 12 & 12 & 38 \\
\hline
\end{tabular}

On the whole, the amount of nitro products was found to decrease with the increasing electron donating ability of the substituents. However, electron-rich 2-alkoxy substituted phenylboronic acids produce relatively low yields with these substrates, apparently because the inductive effect of oxygen may also play a pivotal role in the reaction yield (Table 8 ).

A simple and convenient method for the conversion of arylboronic acid to nitroarenes using $\mathrm{Bi}\left(\mathrm{NO}_{3}\right)_{3} \cdot 5 \mathrm{H}_{2} \mathrm{O} / \mathrm{K}_{2} \mathrm{~S}_{2} \mathrm{O}_{8}$ as the nitrating agent was reported by Manna et al. in $2012 .{ }^{37}$ In their research, this ipso-nitration protocol was investigated in the context of reactions of phenylboronic acid with different nitrate sources in various solvents. The best result was achieved with $1 \mathrm{mmol}$ of $\mathrm{Bi}\left(\mathrm{NO}_{3}\right)_{3} \cdot 5 \mathrm{H}_{2} \mathrm{O}$ with $0.5 \mathrm{mmol}$ of the arylboronic acids at $80^{\circ} \mathrm{C}$. Other nitrate sources such as NaNO3, $\mathrm{Pb}(\mathrm{NO} 3) 2, \mathrm{NaNO} 2$, and AgNO2 failed to yield the nitro products. However, if $\mathrm{Cd}(\mathrm{NO} 3) 2$ was used as the nitrating agent at $100^{\circ} \mathrm{C}$, nitro products was formed in a yield of 51\%, while a better result was obtained with AgNO3 under the same reaction conditions. Herein, ipso-nitration proceed successfully in solvents such as toluene, o-xylylene, benzene, and trifluorotoluene, but it was observed that temperatures higher than $80{ }^{\circ} \mathrm{C}$ led to lower conversion due to increased protodeboronation reactions, therefore, only toluene and benzene were used in further investigations. Furthermore, the $\mathrm{Bi}\left(\mathrm{NO}_{3}\right)_{3} \cdot 5 \mathrm{H}_{2} \mathrm{O} / \mathrm{K}_{2} \mathrm{~S}_{2} \mathrm{O}_{8}$ catalyzed transformation of arylboronic acids to nitroaromatics has also been studied (Table 9).

ipso-Nitration of the heterocyclic, alkyl, and aryl substituted arylboronic acids formed products in good to excellent yields (63-96\%), including with base-sensitive functional groups such as keto with an acidic alkyl and ester group (Table 9). 
Table 9. ipso-Nitration of arylboronic acids
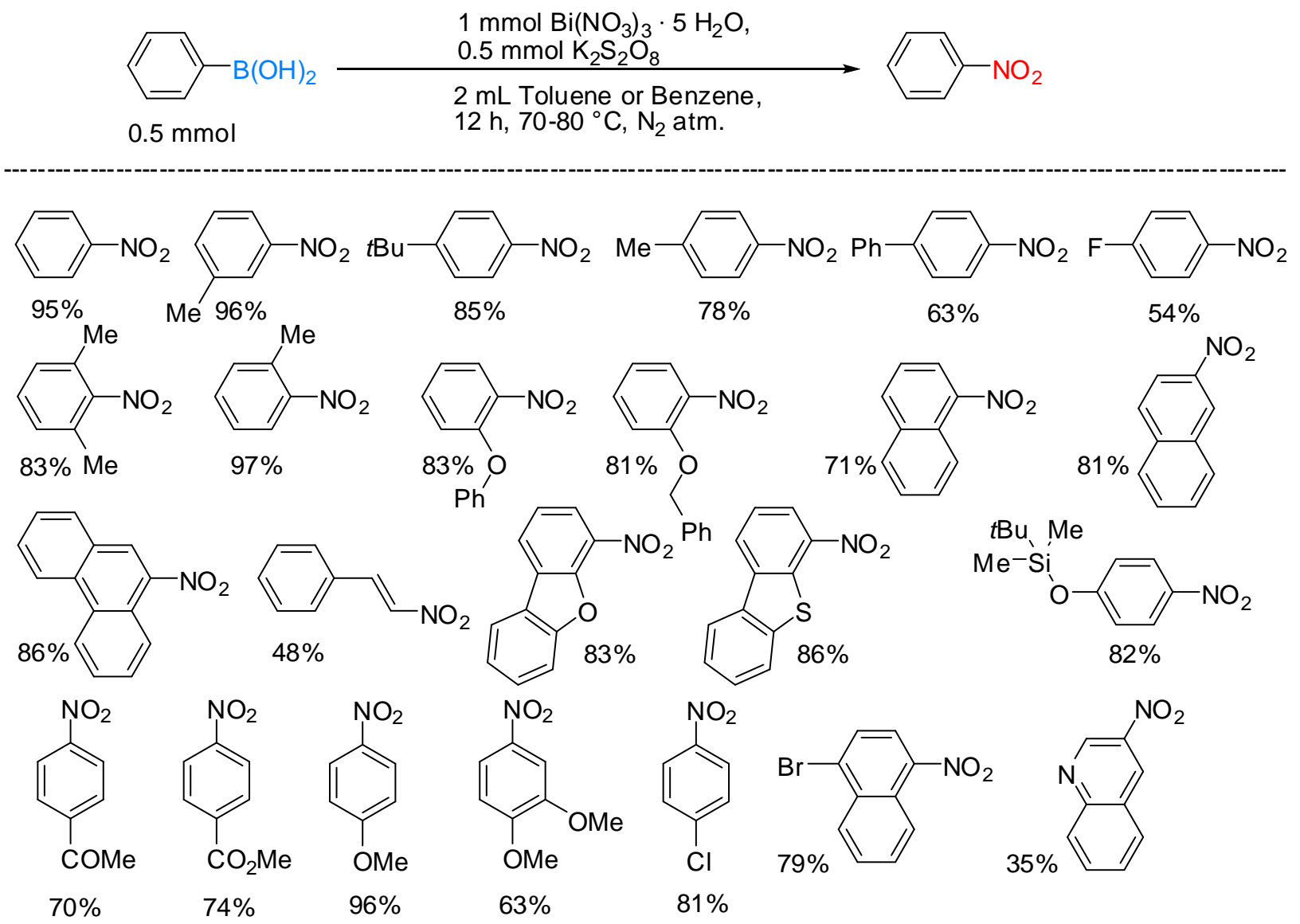

The mechanism of ipso-nitration of arylboronic acid (Scheme 13) is believed to be akin to the radicalbased mechanisms like those involving the use of 2,2,6,6-tetramethylpiperidin-1-yl)oxyl (TEMPO), hydroquinone, and thiourea. The addition of hydroquinone or TEMPO with $\mathrm{PhB}(\mathrm{OH})_{2}$ resulted in the formation of the desired $\mathrm{PhNO}_{2}$ product. In such a reaction, in the presence of bismuth (III) salts, persulfate anion disproportionates into sulfate dianion and sulfate radical anion. This radical could then react with the boronic acid through an unexplored process (which is expected to be the subject of future investigations), providing an aryl radical.

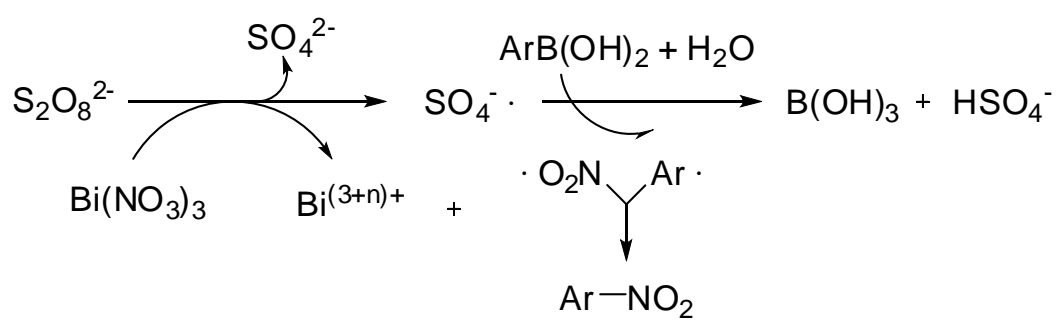

Scheme 13. Proposed mechanism for ipso-nitration of arylboronic acid.

Yadav et al. developed a catalyst-free ipso-nitration of the phenyl boronic acids using different nitrate sources such as zirconium nitrate, potassium nitrate, sodium nitrate, cerric ammonium nitrate, silver nitrate, bismuth subnitrate, and bismuth (III) nitrate. ${ }^{38}$ Toluene was chosen as the reaction medium for the related 
optimization studies. Formed nitroarenes from various substituted phenyl and heteroaryl boronic acids are shown in Table 10.

Table 10. Nitroarenes synthesized from arylboronic acids.

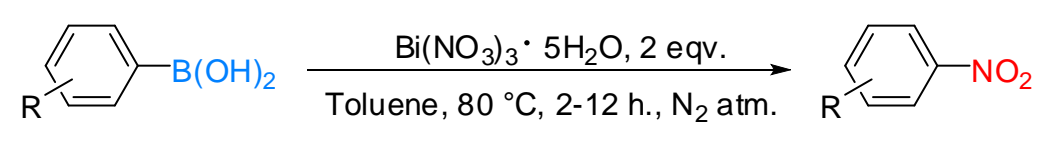

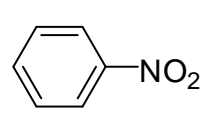

$90 \%$

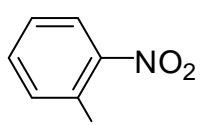

$90 \% \mathrm{Me}$

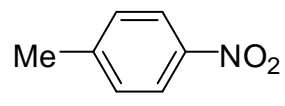

$87 \%$

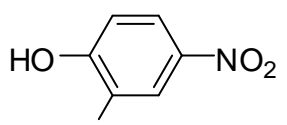

$\mathrm{O}_{2} \mathrm{~N} 77 \%$<smiles>O=[N+]([O-])c1ccc2c(c1)OCO2</smiles>

$81 \%$

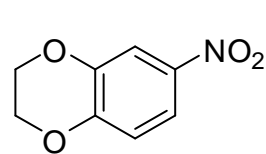

$87 \%$

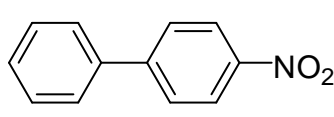

$83 \%$

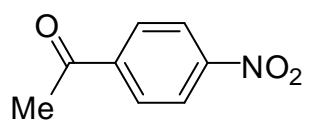

$87 \%$<smiles>O=[N+]([O-])c1cccc2c1oc1ccccc12</smiles>

$70 \%$<smiles>O=[N+]([O-])c1ccc2ccccc2c1</smiles>

$83 \%$<smiles>Cc1ccccc1[N+](=O)[O-]</smiles>

$0 \% \mathrm{CHO}$<smiles>O=[N+]([O-])c1cncc2ccccc12</smiles>

$68 \%$

It was observed that $\mathrm{Bi}\left(\mathrm{NO}_{3}\right)_{3} \cdot 5 \mathrm{H}_{2} \mathrm{O}$ was the best nitrating agent for ipso-nitration, and 2 equiv of $\mathrm{Bi}\left(\mathrm{NO}_{3}\right)_{3} \cdot 5 \mathrm{H}_{2} \mathrm{O}$ in toluene as a solvent, as well as reflux at $80^{\circ} \mathrm{C}$ for $2 \mathrm{~h}$, were chosen as the conditions for further studies.

The mechanism of ipso-nitration by $\mathrm{Bi}\left(\mathrm{NO}_{3}\right)_{3} \cdot 5 \mathrm{H}_{2} \mathrm{O}$ is illustrated in Scheme 14. At first, the researchers investigated whether the catalyst-free ipso-nitration occurs via a free-radical mechanism; the reaction of phenylboronic acid was performed in the presence of the free-radical scavengers TEMPO and thiourea. The reaction took place smoothly in the presence of TEMPO and thiourea, thus ruling out the possibility of a freeradical mechanism. The fact that aliphatic boronic acid did not participate in this reaction indicates that the aromatic ring plays an important electronic role in the ipso-nitration and that bismuth nitrate is presumably responsible for the in situ production of $\mathrm{Bi}-\mathrm{O}-\mathrm{NO}_{2}$ species. Insofar as boron is highly oxophilic, it is likely that through electronic interactions between the boronic acid group and the species of $\mathrm{Bi}-\mathrm{O}-\mathrm{NO}_{2}$, be formed an ionic species, which helps to occur the ipso-nitration reactions.

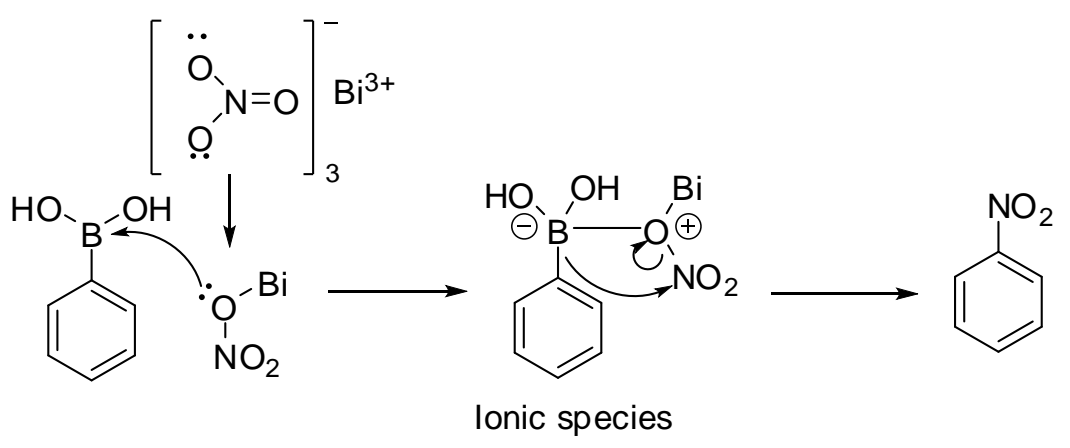

Scheme 14. Proposed mechanism for ipso-nitration of arylboronic acids by $\mathrm{Bi}\left(\mathrm{NO}_{3}\right)_{3} \cdot 5 \mathrm{H}_{2} \mathrm{O}$. 
Chatterjee et al. reported a highly efficient [bis-(trifluoroacetoxy)]iodobenzene (PIFA)-mediated oxidative regioselective nitration of aryl-, alkyl- and heteroarylboronic acids, with their first example being the use of a PIFA-NBS-NaNO 2 combination to generate nitroarenes under transition metal-free conditions. ${ }^{39}$ In their study, it was observed that the presence as well as the amount of an additive (NBS) is important for better conversion of the organoboronic acids to the nitroarenes. Increasing the amount of NBS to 2.1 eq. and that of PIFA to 3.0 eq. resulted in quantitative ipso-nitration of the $m$-tolylboronic acid. In addition, the PIFA-mediated ipso-nitration of aryl-, alkyl- and heteroarylboronic acids with either an electron donating or withdrawing group, which was investigated in their work, was found to generate nitro compounds in excellent yields (7494\%) (Table 11).

The preliminary mechanism of these previously investigated reactions probably takes place via the generation of an O-centered radical in the presence of NBS and PIFA; this further reacts with the nitro radical, which itself is formed through the one-electron oxidation of $\mathrm{NaNO}_{2}$ in the presence of PIFA, to form the metastable species A.

Table 11. ipso-Nitration of aryl-, alkyl- and heteroarylboronic acids

$$
\mathrm{R}-\mathrm{B}(\mathrm{OH})_{2} \stackrel{\mathrm{Phl}\left(\mathrm{OCOCF}_{3}\right)_{2}, \mathrm{NBS} \mathrm{NaNO}_{2},}{\mathrm{MeCN}, \text { r.t., } 3 \mathrm{~h}} \mathrm{R}-\mathrm{NO}_{2}
$$

$\mathrm{R}=\mathrm{alkyl}$, aryl, heteryl

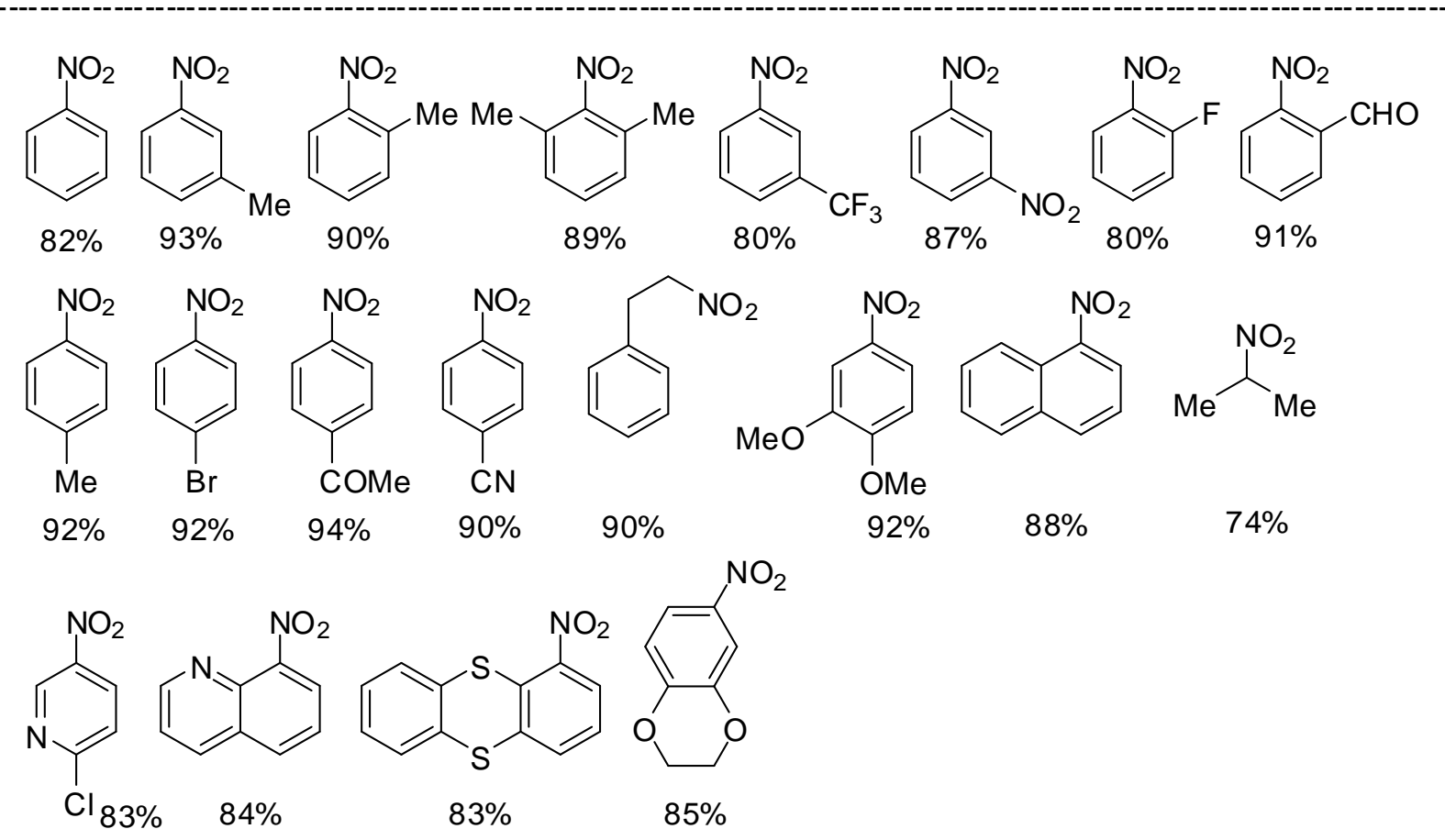

After all, as shown in Scheme 15, the nitroarenes are formed via nitro transfer to the aryl moiety through 1,3-aryl migration from the tetra-coordinated species $B$, which is itself produced from $A$ through coordination by the succinimide. 


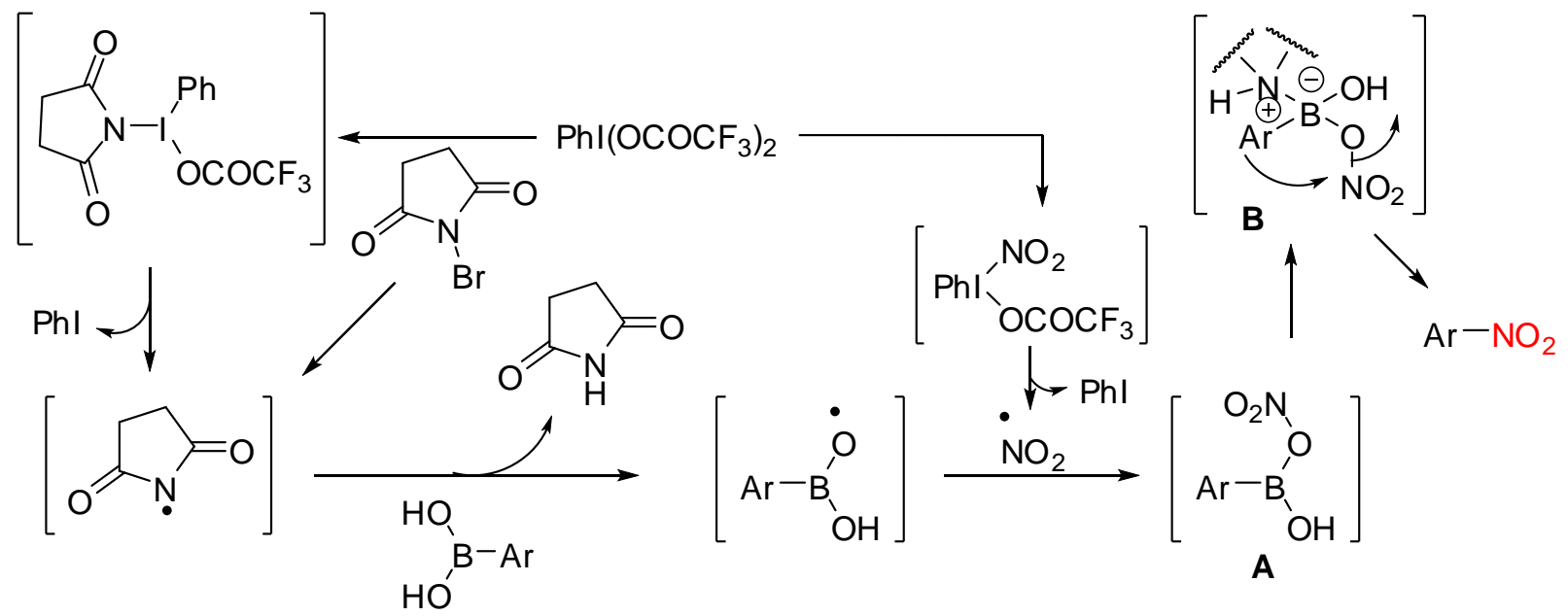

Scheme 15. Mechanism of the ipso-nitration of organoboronic acids in the presence of NBS.

Recently, Yang and colleagues reported a simple, efficient, and practical ipso-nitration of arylboronic acids with 0.5 equiv. of iron nitrate without the addition of any additive. ${ }^{40}$ At first, 4-methylboronic acid was selected as a substrate and the reaction conditions were studied systematically with a variety of nitrate salts and solvents; in addition, various reaction temperatures and atmospheres were also screened (Table 12).

Table 12. ipso-Nitration of 4-methylboronic acid with various nitrate salts

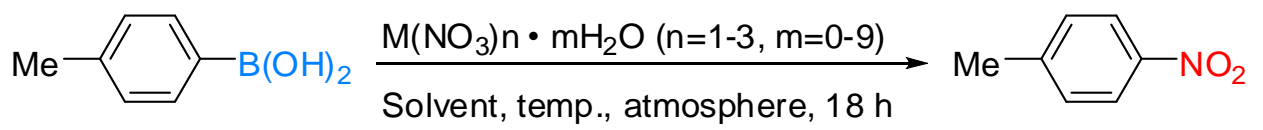

\begin{tabular}{ccccc}
\hline Entry & $\mathrm{M}\left(\mathrm{NO}_{3}\right)_{\mathrm{n}} \cdot \mathrm{mH}_{2} \mathrm{O}$ (equiv.) & Solvent & $\begin{array}{c}\text { Temp. } \\
\left({ }^{\circ} \mathrm{C}\right)\end{array}$ & $\begin{array}{c}\text { Yield } \\
(\%)\end{array}$ \\
\hline 1 & $\mathrm{Fe}\left(\mathrm{NO}_{3}\right)_{3} \cdot 9 \mathrm{H}_{2} \mathrm{O}$ (1 eq.) & Toluene & 80 & 93 \\
2 & $\mathrm{Cu}\left(\mathrm{NO}_{3}\right)_{2} \cdot 3 \mathrm{H}_{2} \mathrm{O}(1.5$ eq. $)$ & Toluene & 80 & 75 \\
3 & $\mathrm{Ni}\left(\mathrm{NO}_{3}\right)_{2} \cdot 6 \mathrm{H}_{2} \mathrm{O}(1.5$ eq. $)$ & Toluene & 80 & 20 \\
4 & $\mathrm{Mg}\left(\mathrm{NO}_{3}\right)_{2}(1.5$ eq. $)$ & Toluene & 80 & 0 \\
5 & $\mathrm{Co}\left(\mathrm{NO}_{3}\right)_{2} \cdot 6 \mathrm{H}_{2} \mathrm{O}(1.5$ eq. $)$ & Toluene & 80 & 70 \\
6 & $\mathrm{Zn}\left(\mathrm{NO}_{3}\right)_{2} \cdot 6 \mathrm{H}_{2} \mathrm{O}(1.5$ eq. $)$ & Toluene & 80 & 10 \\
7 & $\mathrm{NH}_{4} \mathrm{NO}_{3}(3$ eq. $)$ & Toluene & 80 & Trace \\
8 & $\mathrm{AgNO}_{3}(3$ eq. $)$ & Toluene & 80 & 74 \\
9 & $\mathrm{KNO}_{3}(3$ eq. $)$ & Toluene & 80 & Trace \\
10 & $\mathrm{Fe}\left(\mathrm{NO}_{3}\right)_{3} \cdot 9 \mathrm{H}_{2} \mathrm{O}(1$ eq. $)$ & Toluene & 80 & $50^{\mathrm{a}}$ \\
11 & $\mathrm{Fe}\left(\mathrm{NO}_{3}\right)_{3} \cdot 9 \mathrm{H}_{2} \mathrm{O}(1$ eq. $)$ & Toluene & 80 & $40^{\mathrm{b}}$ \\
12 & $\mathrm{Fe}\left(\mathrm{NO}_{3}\right)_{3} \cdot 9 \mathrm{H}_{2} \mathrm{O}$ (1 eq.) & MeCN & 80 & 20 \\
13 & $\mathrm{Fe}\left(\mathrm{NO}_{3}\right)_{3} \cdot 9 \mathrm{H}_{2} \mathrm{O}$ (1 eq.) & c-Hexane & 80 & 78 \\
14 & $\mathrm{Fe}\left(\mathrm{NO}_{3}\right)_{3} \cdot 9 \mathrm{H}_{2} \mathrm{O}$ (1 eq.) & MeOH & 80 & 16 \\
\hline
\end{tabular}


Table 12. Continued

\begin{tabular}{ccccc}
\hline Entry & $\mathrm{M}(\mathrm{NO} 3) \mathrm{n} \cdot \mathrm{mH} 2 \mathrm{O}$ (equiv.) & Solvent & $\begin{array}{c}\text { Temp. } \\
\left({ }^{\circ} \mathrm{C}\right)\end{array}$ & $\begin{array}{c}\text { Yield } \\
(\%)\end{array}$ \\
\hline 15 & $\mathrm{Fe}\left(\mathrm{NO}_{3}\right)_{3} \cdot 9 \mathrm{H}_{2} \mathrm{O}(1$ eq. $)$ & $\mathrm{H}_{2} \mathrm{O}$ & 80 & 0 \\
16 & $\mathrm{Fe}\left(\mathrm{NO}_{3}\right)_{3} \cdot 9 \mathrm{H}_{2} \mathrm{O}(1$ eq. $)$ & Toluene & 100 & 89 \\
17 & $\mathrm{Fe}\left(\mathrm{NO}_{3}\right)_{3} \cdot 9 \mathrm{H}_{2} \mathrm{O}(1$ eq. $)$ & Toluene & 60 & 24 \\
18 & $\mathrm{Fe}\left(\mathrm{NO}_{3}\right)_{3} \cdot 9 \mathrm{H}_{2} \mathrm{O}(0.5$ eq. $)$ & Toluene & 80 & 92 \\
19 & $\mathrm{Fe}\left(\mathrm{NO}_{3}\right)_{3} \cdot 9 \mathrm{H}_{2} \mathrm{O}(0.3$ eq. $)$ & Toluene & 80 & 68 \\
\hline
\end{tabular}

a Under air. ${ }^{b}$ Under oxygen atmosphere.

If the reaction was performed under air or oxygen atmosphere, the final product yields were reduced. When 4-methylboronic acid was reacted with $\mathrm{Fe}\left(\mathrm{NO}_{3}\right)_{3} \cdot 9 \mathrm{H}_{2} \mathrm{O}$ under a nitrogen atmosphere in toluene (at 80 ${ }^{\circ} \mathrm{C}$ ), however, nitro products were obtained at a yield of $93 \%$. Therefore, it was selected as the optimal conditions for further ipso-nitration reaction. For instance, screening of the ipso-nitration of arylboronic acids with electron-donating and electron-withdrawing groups indicated that final products were obtained in higher yields with the arylboronic acids with electron-donating groups than with those containing electronwithdrawing groups (Table 13).

Table 13. ipso-Nitration of arylboronic acids with iron nitrate
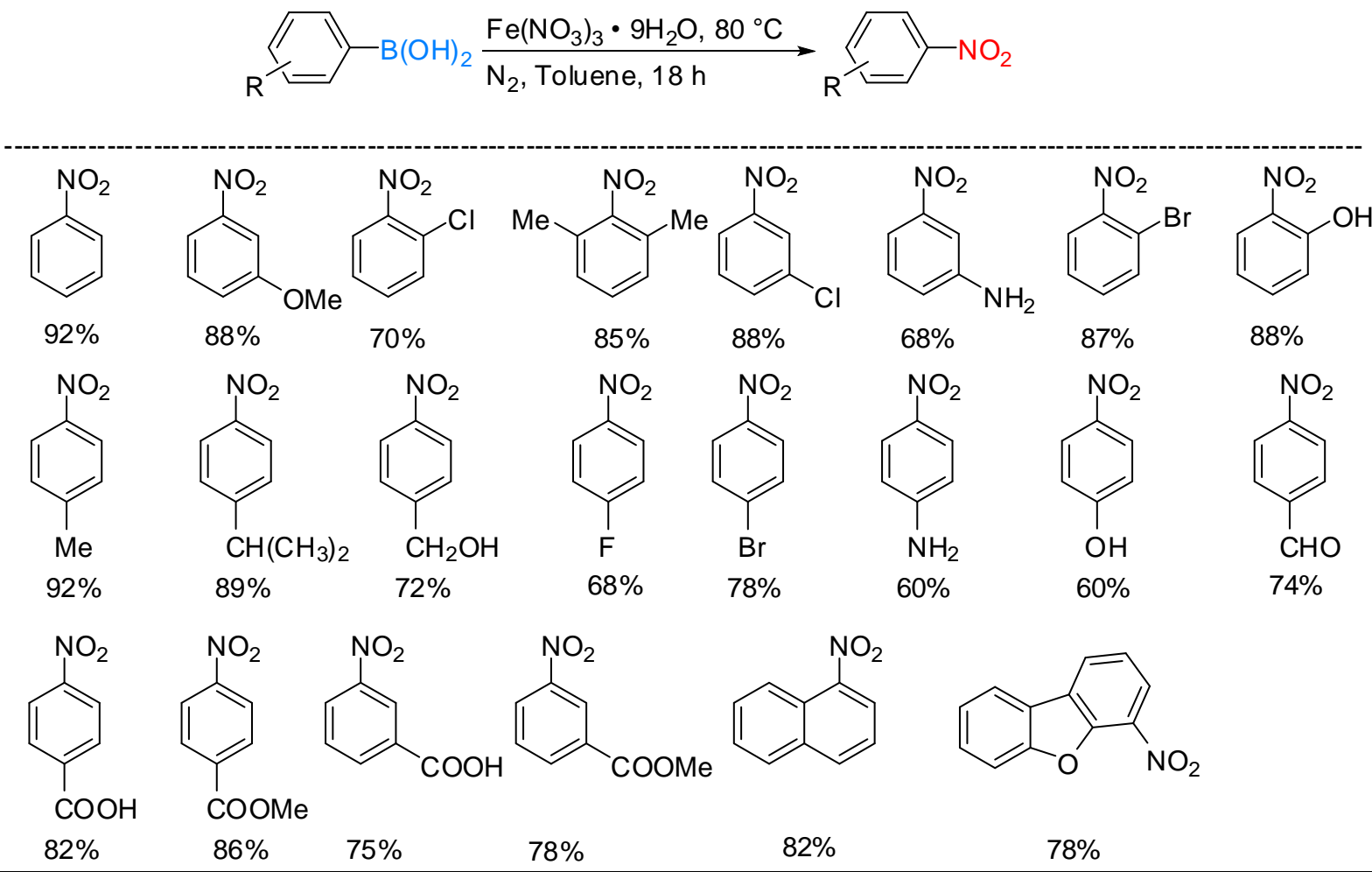

A possible mechanism for the ipso-nitration of arylboronic acids with iron nitrate, probably follows a path similar to the following: under heating $\mathrm{Fe}\left(\mathrm{NO}_{3}\right)_{3}$ produces $\mathrm{Fe}\left(\mathrm{NO}_{3}\right)_{2}(\mathbf{a})$ and the radical $\mathrm{NO}_{3}$ (b) that dimerizes to $\mathbf{c}$, which then decomposes to $\mathrm{NO}_{2}$ (d) releasing oxygen (Scheme 16). 


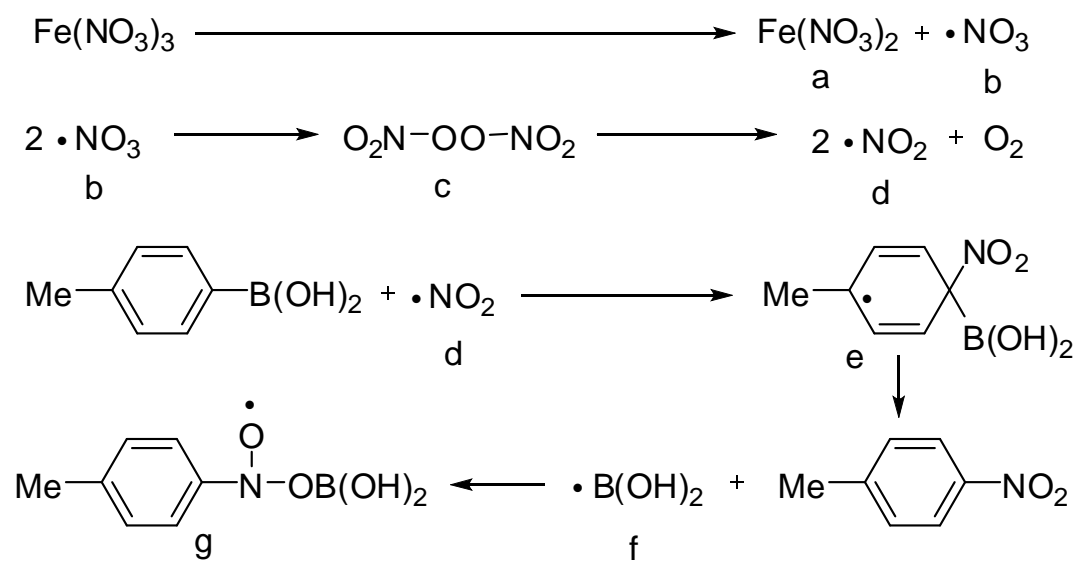

Scheme 16. Possible mechanism for ipso-nitration of arylboronic acids with iron nitrate.

Next $\mathrm{NO}_{2}$ (d) reacts with 4-methylphenylboronic acid to produce the cyclohexadienyl (e) radical, that loses the radical $\mathrm{B}(\mathrm{OH})_{2}(\mathbf{f})$, affording the reaction product. The interaction of radical $\mathrm{B}(\mathrm{OH})_{2}(\mathbf{f})$ with the reaction product, would then lead to the detected boroxynitroxide $(\mathbf{g})$ (Scheme 16).

In 2007, Bougdid et al. presented the first ipso-nitration of 2,2-diphenyl-2H-1-benzopyrans. ${ }^{41}$ They $^{2}$ selected Crivello's reagent $\left(\mathrm{NH}_{4} \mathrm{NO}_{3} /\left(\mathrm{CF}_{3} \mathrm{CO}\right)_{2} \mathrm{O}\right)$ as the nitrating agent. At first, trifluoroacetic anhydride was slowly added to a mixture of $\mathrm{NH}_{4} \mathrm{NO}_{3}$ (1.1 equiv) in acetonitrile. Thereafter, boronic acid (1 equiv) was reacted with the prepared nitrating agent at $-35^{\circ} \mathrm{C}$, forming only selective mono nitro products (Scheme 17).
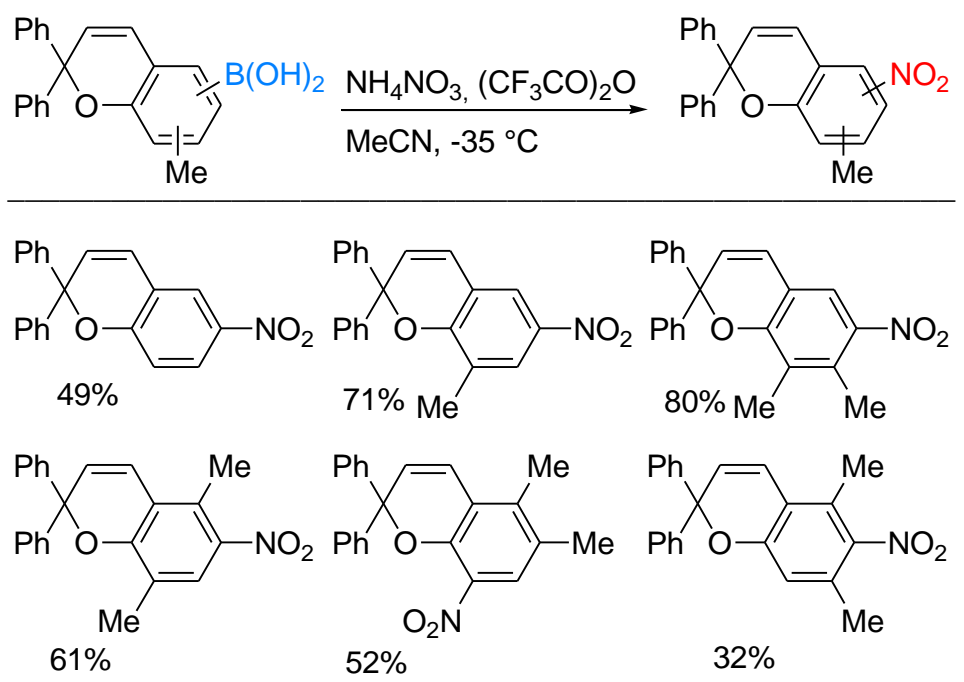

Scheme 17. ipso-Nitration of 2,2-diphenyl-2H-1-benzopyrans.

\section{Conclusions}

In summary, the recent advances in ipso-nitration reactions, including those carried out via both classical and modern methods have been highlighted in this review. The most commonly used traditional ipso-nitration reaction involves the synthesis of nitrocalixarenes, whereas arylboronic acids are preferred in the more modern approaches using various metal salts and mild nitrating agents. In the 1990s, it was observed that, in a 
lot of experimental investigations, only alkyl groups were transformed into nitro groups by ipso-nitration. However, this type of reaction has been noticeably developed in more recent years, and now various functional groups, such as hydroxyl, carbonyl, carboxyl, cycloalkane, and halo-derivatives, can be converted into selective nitro products, whereby can be used as building blocks in organic synthesis. Thus, our research group believes that, in organic synthesis methodology, the conversion of any functional group into a nitro group will always be an important point to consider, which is why perspectives on ipso-nitration will continue to develop in the future.

\section{Acknowledgments}

This work was supported by the National Natural Science Foundation of China (NSFC) (Grant No. 21550110495) and funded by the Chinese Academy of Sciences President's International Fellowship Initiative (Grant No. 2016PT014) and the Central Asia Drug Research and Development Center of the Chinese Academy of Sciences.

\section{References}

1. Hoggett, J. Nitration and aromatic reactivity; Cambridge University Press, 1971.

2. Olah, G. A.; Malhotra, R.; Narang, S. C. Nitration: Methods and Mechanisms; Wiley-VCH, 1989.

3. Yan, G.; Yang, M. Org. Biomol. Chem. 2013, 11, 2554.

http://dx.doi.org/10.1039/C30B27354G

4. Yan, G.; Borah, A. J.; Wang, L. Org. Biomol. Chem. 2014, 12, 6049.

http://dx.doi.org/10.1039/C40B00573B

5. Bernacki, R. J.; Pera, P.; Gambacorta, P.; Brun, Y.; Greco, W. R. Ann. N. Y. Acad. Sci. 2000, $922,293$.

http://dx.doi.org/10.1111/j.1749-6632.2000.tb07046.x

6. Squella, J. A.; Bollo, S.; Nunez-Vergara, L. J. Curr. Org. Chem. 2005, 9, 565.

http://dx.doi.org/10.2174/1385272053544380

7. Patterson, S.; Wyllie, S. Trends Parasitol. 2014, 30, 289.

http://dx.doi.org/10.1016/i.pt.2014.04.003

8. Mathivanan, N. Ipso-nitration of phenols, phenolic ethers and phenoxy acids: formation and reactions of ipso-nitro adducts; National Library of Canada, 1989.

9. Waller, A. Ph.D. Thesis, University of Canterbury, 1989.

10. Iyer, L. M. Formation and reactions of adducts from ipso nitration of nitroarenes, University of Victoria (B.C., Canada), 1980.

11. Coquière, D.; Marrot, J.; Reinaud, O. Org. Lett. 2007, 9, 3271.

http://dx.doi.org/10.1021/ol071208t

12. Le Gac, S.; Zeng, X.; Reinaud, O.; Jabin, I. J. Org. Chem. 2005, 70, 1204.

http://dx.doi.org/10.1021/jo048137l

13. Podoprygorina, G.; Zhang, J.; Brusko, V.; Bolte, M.; Janshoff, A.; Böhmer, V. Org. Lett. 2003, 5, 5071. http://dx.doi.org/10.1021/ol0361002

14. Rashidi-Ranjbar, P.; Taghvaei-Ganjali, S.; Shaabani, B.; Akbari, K. Molecules 2000, 5, 941. 
http://www.mdpi.com/1420-3049/5/7/941

15. Danila, C.; Bolte, M.; Bohmer, V. Org. Biomol. Chem. 2005, 3, 172.

http://dx.doi.org/10.1039/B414173C

16. Hudecek, O.; Budka, J.; Eigner, V.; Lhoták, P. Tetrahedron 2012, 68, 4187.

http://dx.doi.org/10.1016/j.tet.2012.03.102

17. Lejeune, M.; Picron, J.-F.; Mattiuzzi, A.; Lascaux, A.; De Cesco, S.; Brugnara, A.; Thiabaud, G.; Darbost, U.; Coquière, D.; Colasson, B.; Reinaud, O.; Jabin, I. J. Org. Chem. 2012, 77, 3838.

http://dx.doi.org/10.1021/jo300179h

18. Brugnara, A.; Fusaro, L.; Luhmer, M.; Prange, T.; Colasson, B.; Reinaud, O. Org. Biomol. Chem. 2014, 12, 2754.

http://dx.doi.org/10.1039/C40B00304G

19. Yamato, T.; Tsuchihashi, K.; Nakamura, N.; Hirahara, M.; Tsuzuki, H. Can. J. Chem. 2002, 80, 207. http://dx.doi.org/10.1139/v02-009

20. Sawada, T.; Hongo, T.; Matsuo, N.; Konishi, M.; Kawaguchi, T.; Ihara, H. Tetrahedron 2011, 67, 4716. http://dx.doi.org/10.1016/j.tet.2011.04.025

21. Redon, S.; Li, Y.; Reinaud, O. J. Org. Chem. 2003, 68, 7004.

http://dx.doi.org/10.1021/jo034557j

22. Kumar, S.; Varadarajan, R.; Chawla, H. M.; Hundal, G.; Hundal, M. S. Tetrahedron 2004, 60, 1001. http://dx.doi.org/10.1016/j.tet.2003.11.057

23. Elmuradov, B. Z.; Bozorov, K. A.; Kurbanbayeva, A.; Ortikov, I.; Bobakulov, K.; Abdullayev, N.; Yili, A.; Aisa, H. A.; Shakhidoyatov, K. M. Am. Chem. Sci. J. 2013, 3, 364.

http://dx.doi.org/10.9734/ACSJ/2013/4203

24. Elmuradov, B. Z.; Bozorov, K. A.; Okmanov, R. Y.; Tashkhodjaev, B.; Shakhidoyatov, K. M. Acta Crystallographica Section E 2011, 67, 0824.

http://dx.doi.org/10.1107/S1600536811007902

25. Mamarahmonov, M. K.; Belen'kii, L. I.; Chuvylkin, N. D.; Ashirmatov, M. A.; Elmuradov, B. Z.; Ortikov, I.; Kodirov, A.; Shakhidoyatov, K. M. Russ. Chem. Bull., Int. Ed. 2014, 63, 1986.

http://dx.doi.org/10.1007/s11172-014-0689-1

26. Mamarakhmonov, M. K.; Belen'kii, L. I.; Chuvylkin, N. D.; Ashirmatov, M. A.; Elmuradov, B. Z.; Ortikov, I. S.; Shakhidoyatov, K. M. Russ. Chem. Bull., Int. Ed. 2015, 64, 534.

http://dx.doi.org/10.1007/s11172-015-0897-3

27. Messere, A.; Gentili, A.; Garella, I.; Temussi, F.; Di Blasio, B.; Fiorentino, A. Synth. Commun. 2004, 34, 3317.

http://dx.doi.org/10.1081/SCC-200030569

28. Bose, A. K.; Ganguly, S. N.; Manhas, M. S.; Srirajan, V.; Bhattacharjee, A.; Rumthao, S.; Sharma, A. H. Tetrahedron Lett. 2004, 45, 1179.

http://dx.doi.org/10.1016/j.tetlet.2003.12.002

29. Bose, A. K.; Ganguly, S. N.; Manhas, M. S.; He, W.; Speck, J. Tetrahedron Lett. 2006, 47, 3213.

http://dx.doi.org/10.1016/j.tetlet.2006.03.059

30. Asghedom, H.; LaLonde, R. T.; Ramdayal, F. Tetrahedron Lett. 2002, 43, 3989. http://dx.doi.org/10.1016/S0040-4039(02)00743-8

31. Natarajan, P.; Chaudhary, R.; Venugopalan, P. J. Org. Chem. 2015, 80, 10498. http://dx.doi.org/10.1021/acs.joc.5b02133 
32. Azad, C. S.; Balaramnavar, V. M.; Khan, I. A.; Doharey, P. K.; Saxena, J. K.; Saxena, A. K. RSC Adv. 2015, 5, 82208.

http://dx.doi.org/10.1039/C5RA18036H

33. Amal Joseph, P. J.; Priyadarshini, S.; Lakshmi Kantam, M.; Maheswaran, H. Tetrahedron Lett. 2012, 53, 1511.

\section{http://dx.doi.org/10.1016/j.tetlet.2012.01.056}

34. Prakash, G. K. S.; Panja, C.; Mathew, T.; Surampudi, V.; Petasis, N. A.; Olah, G. A. Org. Lett. 2004, 6, 2205. http://dx.doi.org/10.1021/ol0493249

35. Crivello, J. V. J. Org. Chem. 1981, 46, 3056.

http://dx.doi.org/10.1021/jo00328a013

36. Prakash, G. K. S.; Gurung, L.; Schmid, P. C.; Wang, F.; Thomas, T. E.; Panja, C.; Mathew, T.; Olah, G. A. Tetrahedron Lett. 2014, 55, 1975.

http://dx.doi.org/10.1016/j.tetlet.2014.01.138

37. Manna, S.; Maity, S.; Rana, S.; Agasti, S.; Maiti, D. Org. Lett. 2012, 14, 1736.

http://dx.doi.org/10.1021/ol300325t

38. Yadav, R. R.; Vishwakarma, R. A.; Bharate, S. B. Tetrahedron Lett. 2012, 53, 5958.

http://dx.doi.org/10.1016/j.tetlet.2012.08.121

39. Chatterjee, N.; Bhatt, D.; Goswami, A. Org. Biomol. Chem. 2015, 13, 4828.

http://dx.doi.org/10.1039/C5OB00337G

40. Jiang, M.; Yang, H.; Li, Y.; Jia, Z.; Fu, H. RSC Adv. 2013, 3, 25602.

http://dx.doi.org/10.1039/C3RA45118F

41. Bougdid, L.; Heynderickx, A.; Delbaere, S.; Moustrou, C. Tetrahedron 2007, 63, 8242.

http://dx.doi.org/10.1016/j.tet.2007.05.113

\section{Authors' Biographies}

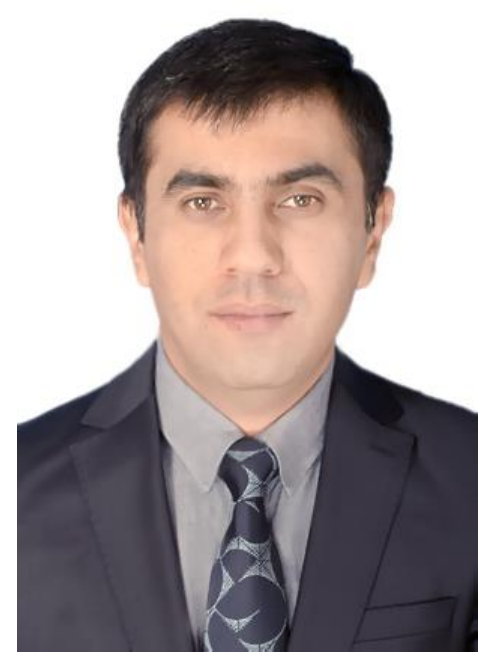

Khurshed Bozorov studied at the Samarkand State University (Uzbekistan), obtaining his BSc and Master Degree in Chemistry in 2005 and 2007, respectively. In 2011 he got PhD in Organic Chemistry under the supervision of Prof. Khusnutdin M. Shakhidoyatov at the Institute of the Chemistry of Plant Substances, 
Academy of Sciences of Uzbekistan. His PhD work was focused on the synthesis and chemical transformation of thienopyrimidines with biological activity. In 2013 he was awarded the Chinese Academy of Sciences Postdoctoral fellowship and joined in the Prof. Haji A. Aisa group at the Xinjiang Technical Institute of Physics and Chemistry, CAS. His main research interests are the chemical synthesis and biological properties of nitrogen and sulfur containing heterocycles as well as drug design on base them.

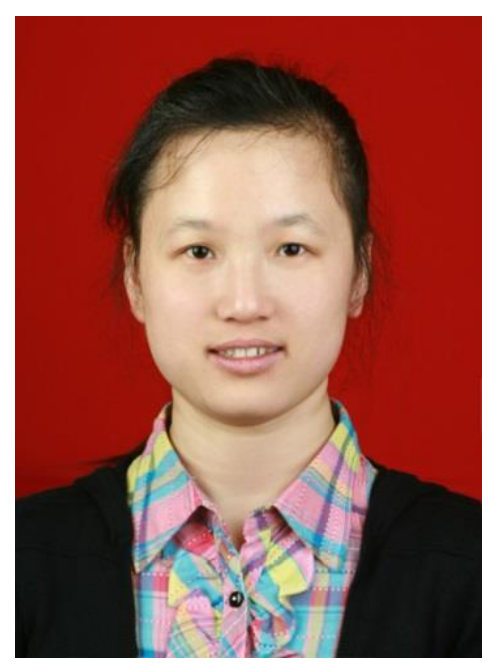

Jiang-Yu Zhao obtained her Master Degree in Organic Chemistry at the Nankai University in 2007. In 2011, she got PhD in Organic Chemistry under the supervision of Prof. Haji A. Aisa and continuing her scientific career at the Xinjiang Technical Institute of Physics and Chemistry, CAS from 2011 until now. Her PhD work was focused on the synthesis and chemical modification of natural products with anti-influenza activities. In 2015, she was awarded project by Youth Innovation Promotion Association, CAS. Her main research interests are the drug design, synthesis and biological screening of active compound from unique medicinal plant resources in Xinjiang.

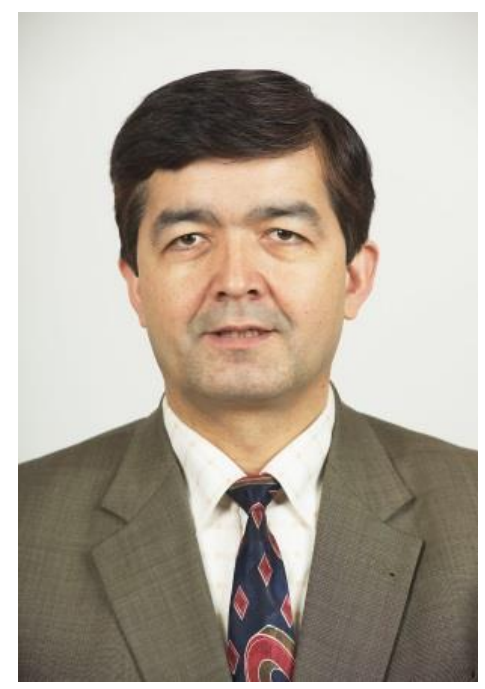

Haji A. Aisa is Deputy-Director of the Xinjiang Technical Institute of Physics and Chemistry, CAS. He obtained his PhD Degree in Organic chemistry at the Shanghai Institute of Materia Medica in 1999. His current research interests are: a) development of bio-resources and indigenous medicinal plants in arid zone and Central Asia; b) the synthesis and drug design in the phytochemistry and organic synthesis; c) investigation and modernization of traditional Uighur medicine. He has published more than 300 scientific articles in domestic 
and foreign academic journals and applied for 126 national patents, in which 75 were licensed and 12 were put in practice. He has been supported by National Science Fund for Distinguished Young Scholars by National Natural Science Foundation of China in 2009. 